This item was submitted to Loughborough's Research Repository by the author.

Items in Figshare are protected by copyright, with all rights reserved, unless otherwise indicated.

\title{
Are there benefits to being naked? The returns and diversification impact of capital structure arbitrage
}

PLEASE CITE THE PUBLISHED VERSION

http://dx.doi.org/10.1080/1351847X.2011.637115

\section{VERSION}

SMUR (Submitted Manuscript Under Review)

\section{PUBLISHER STATEMENT}

This work is made available according to the conditions of the Creative Commons Attribution-NonCommercialNoDerivatives 4.0 International (CC BY-NC-ND 4.0) licence. Full details of this licence are available at: https://creativecommons.org/licenses/by-nc-nd/4.0/

\section{LICENCE}

CC BY-NC-ND 4.0

\section{REPOSITORY RECORD}

Calice, Giovanni, Jing Chen, and Julian M. Williams. 2019. "Are There Benefits to Being Naked? the Returns and Diversification Impact of Capital Structure Arbitrage”. figshare. https://hdl.handle.net/2134/24211. 


\title{
Are There Benefits To Being Naked?
}

The Returns and Diversification Impact of Capital Structure Arbitrage

\author{
Giovanni Calice* \\ School of Management, University of Southampton \\ Jing Chen \\ School of Business and Economics, Swansea University \\ Julian Williams \\ Business School, University of Aberdeen
}

\begin{abstract}
In a naked credit default swap (CDS) position a party pays an income stream to a seller of protection to swap away default risk on an underlying defaultable security without actually holding this reference instrument. Using mark to market returns on a large cross section of CDS positions, held independently from their reference entity, we implement a novel test to establish whether their inclusion in an optimised portfolio is replicable by a large set of alternative assets. Overall, we find significant excess returns of over $28 \%$ per annum against an optimised benchmark, we speculate that it is these characteristics that could be driving a bubble in the CDS market.
\end{abstract}

Keywords: Capital Structure Arbitrage, Credit Default Swaps, Portfolio Management, Large Scale Covariance Estimation, Portfolio Optimisation

JEL Classification: G10, G11, G12, G20

\section{Introduction}

An entirely sensible view of a credit default swap (CDS) contract is to regard it as being equivalent to a short position in a defaultable bond. Thus, in a complete market consisting of a very large cross section of assets from various different classes, the mark to market returns on a naked CDS contract should be redundant.

*Corresponding Author. We have received very helpful input from Stuart Hyde (Manchester Business School) and Mike Adams (Swansea University). We thank seminar participants at the University of Aberdeen, Business School. All errors remain our own.

Email addresses: g.calice@soton.ac.uk (Giovanni Calice), jing.chen@swansea.ac.uk (Jing Chen), julian.williams@abdn.ac.uk (Julian Williams)

Draft

May 5, 2011 
There is, however, growing theoretical and empirical evidence rejecting this canonical representation. It is suggested, by practitioners, academics and politicians, that the perverse incentives generated by the ability to trade protection on a defaultable claim results in an instrument with pricing and co-movement characteristics deviant from its synthetic origins. Observing these properties directly from quoted financial data as a set of decomposed linear correlative relationships is problematic. However, certain artefacts will appear in the pricing trends as the market develops.

This paper provides evidence about the structure of returns on traded CDS positions. More specifically, we attempt to understand whether the inclusion of these assets in portfolios of more conventional assets significantly changes the risk return profile. To our knowledge, this is the first paper of its type and our results are of relevance to investors, issuers, and regulators involved with the CDS market, which as of August 2009, had a total notional amount under protection of approximately 31 trillion US dollars ${ }^{1}$.

Our main finding of systematic excess returns over and decoupling from standard asset classes provides the prima facie evidence for our central argument and for the divergence from the complete market representation of this contract. In ethos, our approach is most similar to Longstaff et al (2010), albeit we concentrate on a much broader profile of CDS contracts on corporate debt. In addition, a precursor of this research is the study by $\mathrm{Yu}$ (2006) that using short equity and CDS positions, find no significant excess returns for this type of strategy over the 2004-2005 period. However, the author's analysis lacks any attempt at the complete market replication of the level of risk and takes no account of the correlation structure.

The importance and contribution of this research is in highlighting the variation in the correlative patterns of returns on CDS positions within a broader portfolio of assets. We show that CDS positions do not exhibit stable correlative relationships with alternate assets and changes in correlations appear to have no predetermined pattern. Notably, this is a result that runs counter to standard models. To our knowledge this is the first extensive study in

\footnotetext{
${ }^{1}$ Depository Trust \& Clearing Corporation, August 2009 CDS Market Report.
} 
this area and our results have significant implications for policy makers and practitioners.

For instance, consider a classic Merton (1973) scenario with a single representative firm raising capital by equity and corporate debt. The companies assets are assumed to be a geometric brownian motion with drift equal to the return on a risk free instrument. Equity can therefore be assumed to be an option on assets. As such, the default risk (in this case it is assumed to be a solvency condition) on corporate debt will be a decreasing function with respect to the equity value (when holding predicted asset volatility and the size of the maturing debt liabilities constant). Accordingly, the value of protection on corporate debt should vary in a non-stochastic manner with equity. In fact, it is this property that forms the basis of the Moody's KMV model of credit ratings and of capital structure arbitrage strategies that exploit perceived misalignments.

Deviations from perfect functional dependency between equity and protection valuations are suggested to be a result of changes in the volatility of the representative firms assets and/or changes in gearing. However, these features should be captured by the cross sectional variation of a wide class of alternative securities (both contingent and non-contingent) traded within the market, effectively providing the factors driving our representative companies asset valuations. For instance, macro volatility should be captured by the relative value of nominal and real government debt and exchange rates. External shocks, such as weather risk and consumer demand will be captured in commodities prices. We uncover this pattern for the period January 1, 2004 to August 1, 2007 and our strategies offer return profiles that are more precise replication of the underlying instrument. Post August 1, 2007, the fund return profiles diverge substantially for all types of risk appetites (including the naive equally weighted strategy).

In this sense, our title is somewhat facetious in the sense that a systematic divergence from market completeness, whilst evidently beneficial for those holding the contract, could be extremely damaging for social welfare as a whole. Consider a consumption model of default risk. If CDS are traded as an asset and an anticipated discount factor is applied then the meaning of this in terms of a naked short position is ambiguous. A non zero expectation of mark to market returns (i.e. the change in the spreads) on a short naked CDS positions has 
profound implications for the market as a whole, given the explicit structure of the contract. Evidence for a lack of replication and returns on holdings inconsistent with other assets lend support to the argument that the dead weight costs associated with CDSs matter more than the actual design of the contract.

The salient point is that if the credit event generating process is inherently coupled to the value of the contract then a stable long run pricing equilibrium cannot exist. In reality, this would redoubtably lead to a sudden collapse in the CDS spreads as the implied level of default risk would be inherently intolerable with respect to the underlying social contract. Effectively, the social welfare implications of a runaway CDS market would lead to its inherent failure.

In this paper, we document the growth in the value of CDS contracts over the January 1, 2004 to April 2, 2010 period. We show that the payoff of mean variance optimised portfolios that include traded CDS positions exhibit a substantially different return and correlation structure than portfolios where the CDS positions are excluded. We utilise the entire CMADataStream data set of single name corporate CDS positions in addition to a large cross section of alternative assets. We then construct a total sample of 1.240 million returnday observations and compute mean variance optimised ex ante rolling portfolios, with and without traded CDS positions.

We employ random resampling and replacement to construct bootstrap intervals to test this hypothesis for a large collection of assets from a wide variety of classes. We advocate that our results are empirically indicative of the leverage cycle with CDS suggested by Geanakoplos (2009). In this context, the deepening of a financial crisis and the associated increase in default risk benefits the capital structure arbitrager by antagonising the naturally occurring misalignment of incentives between speculative traders and net providers of leverage. We document the potential profits that can be made from this misalignment ex ante by recursive analysis. Additionally, we test the significance of the restriction of CDS positions by comparing a systematic restriction of CDS versus a random restriction on a broad set of alternative assets on the weighted and unweighted correlation profile of a fund of funds portfolio. 
The notional value of underlying assets protected by CDS positions is typically far larger than the total value of the underlying debt. Holding default protection on a bond without actually holding the underlying bond, i.e. being naked in the CDS position, is in effect a bet on the deterioration in the credit quality of the underlying reference entity. Holding a CDS position with a variety of assets other than a fully default offsetting position in the underlying name is often referred to as capital structure arbitrage. Generally, the alternative offsetting assets are equity although the strategy can encompass many alternative combinations ${ }^{2}$.

This paper makes four main contributions to the literature.

The first contribution is a framework that robustly estimates the level of excess returns on mark to market CDS positions and the changes in the correlation structure with respect to various alternative assets. We also show a very high degree of diversification of capital risk in large portfolios of alternative assets. This is a very broad market. Yet, we have restricted our scope to CDS traded on the US, UK, EMU and Japan corporate debt. These market segments have had a longer history of actively traded CDS positions. Note that the inclusion of emerging markets does not yield enough pre-crisis trading to fully explore the distribution of returns. As more trading data becomes available we will extend our work to include a wider number of markets and CDS on sovereign debt.

Second, we measure these effects using a novel portfolio bootstrapping approach that generates very large combinations of portfolios and then computes average correlation and return statistics for broad cross sections of assets at relatively (end of day) high frequency observations.

Third, we document a large variety of statistical evidence about the unique time period between 2004 and 2010. During this period, the financial sector has seen the wide spread adoption of standardised credit derivatives contracts, several correlated asset bubbles, a collapse in the liquidity in financial markets and finally the insolvency and bailout of several

\footnotetext{
${ }^{2}$ Generally, practitioners refer to capital structure arbitrage as holding, for example, a short naked CDS position and an equivalent sized position in the equity of the same firm. However, we extend this definition to simply holding a large cross section of CDS and alternative instruments. A better description for this paper could be macro-structure arbitrage as we include a very wide variety of money market and other investment instruments across the financial spectrum.
} 
systemically important financial institutions.

For example, our results indicate that immediately after the Lehman Brothers default the average block cross correlations between collections of CDS and equities drop from around $-10 \%$ to under $-15 \%$ and, for the 2040 block correlations estimated each day, the maximum observed block correlations between CDS and equity also fall from around $20 \%$ towards zero. We believe that this result is of significant interest to academics and practitioners working on portfolio diversification in presence of financial crises.

Finally, we fill a gap in the empirical literature on capital structure arbitrage with CDSs, reconciling this trading approach with theoretical models of market completeness and documenting the potential returns of this type of strategy.

The remainder of this paper is organised as follows. $\S(2)$ adds some background discussion and reviews some of the related literature in this area. $\S(3)$ discusses a trading position in CDS and the associated payoff structure and unit of account. Furthermore, we introduce the idea of a complete market with exogenous risk and demonstrate why the CDS has an exactly computable price when default risk is exogenous. $\S(4)$ describes the data sample and presents our empirical methodology for building portfolios based on a mean variance optimisation framework. We then introduce our return and correlation diagnostics to test whether the CDS position is replicative relative to a broad cross section of alternatives. $\S(6)$ contains our results, analysis and discussion while $\S(7)$ concludes.

\section{Background and Related Literature}

Initial over the counter (OTC) trading in CDSs originated in the mid 1990s as a means through which banks could reduce their holdings of certain types of expensive core capital. As Shadab (2009) notes "CDSs were born in regulatory sin" [Page 411:2]. Bolton and Oehmke (2010) also suggest that when debtors can buy protection on their own debt the empty creditor problem could result in the perverse preference to instigate default. However, Bolton and Oehmke (2010) conclude that CDS serve a useful purpose in providing a means of facilitating appropriate levels of credit to debtors and reducing the 'anxiety' of the creditor, in the Geanakoplos (2009) parlance. Therefore, the classical representation of the spread 
Figure 1: Comparison between the aggregate notional amounts outstanding on interest rate/FOREX, credit $(\mathrm{CDS})$ and equity derivatives. Source: ISDA.

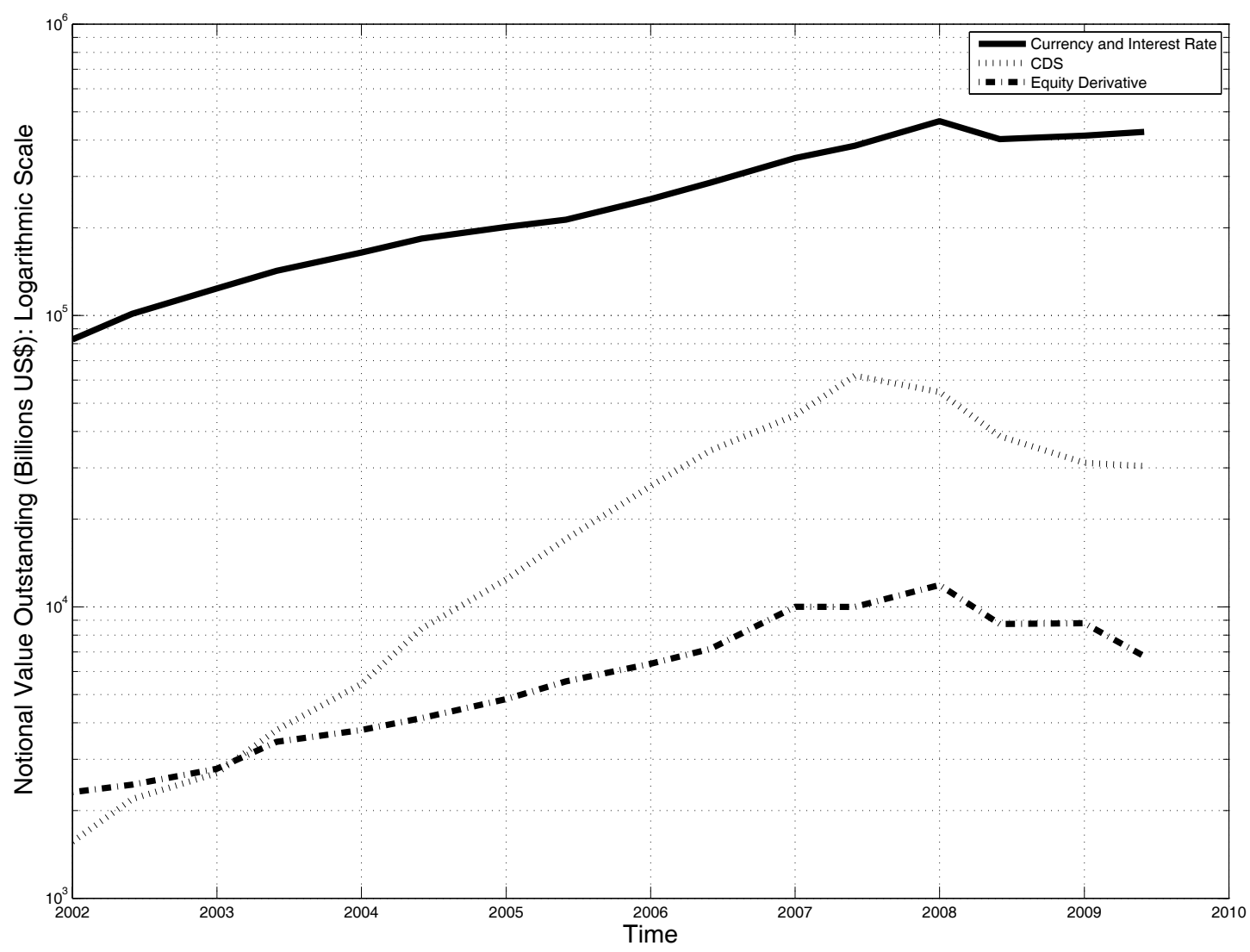

on a CDS as pricing the expectation of default driven by an exogenous stochastic default time is inappropriate. Default risk would, in practice, exhibit a nonlinear state dependent correlation with its own spread as payoffs were tipped in various directions. Thus the returns on CDS positions would exhibit a state dependent correlation with other assets in the market and would at times decouple completely from their underlying positions.

The anecdotal and empirical evidence that CDS positions do more than simply act as a short bond position has negative as well as positive connotations. Several recent articles such as $\mathrm{Hu}$ and Black (2008) and Bolton and Oehmke (2010) point out that the trading of CDS positions results in a classic empty creditor problem. In this case, the debt holder acquires default protection but retains various control rights in the event of default. Once the value of the insurance has been established the creditor may proactively seek default 
to trigger the payoff. At a macro level, this may result in the contagious manipulation of credit markets to drive default risk higher and allow speculators to book profits on default protection purchased at a cheaper rate.

Furthermore, a relevant implication of the analysis provided in Geanakoplos (2009) is that the CDS is no longer serving as a redundant asset replicating the payoff of a short position in defaultable debt. The major reason posited for this divergence from its synthetic roots is that the CDS was introduced part way through the leverage cycle, an economic cycle first introduced in Geanakoplos (1997) and further developed in Fostel and Geanakoplos (2008). An important element for validating this approach is establishing whether the CDS is actually a separate asset class or simply a redundant linear combination of alternative assets.

In this paper, we investigate empirically whether buying a broad baskets of short naked CDS positions provides a significant offsetting of capital risk and potential returns in a large portfolio of different assets ${ }^{3}$. In particular, we postulate a fund that buys and holds a set of naked CDS positions at a particular set of spreads for one day and then either sells or offsets it with the following day's market spreads. The difference is then reinvested into the same strategy. Hence, the value of the fund tracks the change in spreads of the underlying assets. If a credit event occurs then the position returns the notional value invested and this is invested into alternative positions within the fund's portfolio. For the alternative assets we follow the ethos of Pesaran, Schleicher and Zaffaroni (2009), by choosing a broad set of investible assets that span multiple asset classes with daily data, albeit in our case across a far larger cross section. Pesaran, Schleicher and Zaffaroni (2009) solve for portfolios and test the efficacy of multiple dynamic covariance models. Yet, the cross sectional magnitude of our portfolios is far larger and it is computationally impractical to optimise across multiple model classes. Hence, in our framework we use an exponentially weighted moving average and optimise across the single decay parameter.

We take an agnostic view on the morality of such positions and simply seek to quantify the

\footnotetext{
${ }^{3}$ Capital risk is the variation in the value of a portfolio due to market fluctuations in the constituent assets.
} 
potential gains associated to these positions. We utilise the entire CMA database provided by Thompson Reuters from 2004 onwards and build sector level portfolios of CDS positions for the US, UK, European Monetary Union (EMU) and Japan. The portfolios can be regarded as exchange traded funds (ETFs) with exposure to changes in the spreads on protection of the underlying corporate debt. We mix these CDS funds into a larger pool of funds covering five other asset classes. We take the position of a fund of funds rebalancing its portfolio across these available assets, using a standard mean variance approach. As a reference portfolio, we then build an alternative fund of funds with the CDS positions restricted to a zero holding and rebalancing across the remaining unrestricted instruments.

For brevity, we liberally interchange between "fund" and "basket". In both senses, we are referring to an individual collection of tradeable positions. For example, we can think of an individual synthetic fund investing in CDSs of varying maturities on bonds issued by EMU automotive firms. In this sense, basket refers to the collection of tradeable positions and fund refers to the dollar return on those positions. The complete list of funds/baskets included in this study is reported in Table B.6 and its construction is discussed in more detail in $\S(3)$. We also refer to a block of funds in terms of asset class, e.g. CDS or equity. However, this again is slightly disingenuous as, for example, the commodities and foreign exchange funds are tracking indices that include a variety of spot, forward and future rates. Furthermore, we divide most of our estimated results over two sample periods: from January 1, 2004 to July 31, 2007 and from August 1, 2007 to April 2, 2010. Whilst there is not a clear-cut consensus as to the exact starting point of the financial crisis, the summer of 2007 seems to be a reasonable choice to partition our analysis and prima facie evidence from the evolution of our portfolios supports this assumption.

To the best of our knowledge, empirical work on portfolio diversification and CDS as tradeable assets is non-existent. Although CDSs can introduce an extra diversification component in portfolios an argument against credit risk transfer (CRT) via CDSs is that it leads to greater retention by financial institutions of "toxic waste" assets that are particularly illiquid and vulnerable to macroeconomic performance. Wagner (2007) shows that the increased portfolio diversification possibilities introduced by CRT can increase the proba- 
bility of liquidity based crises. The reason is that the increased diversification leads banks to reduce the amount of liquid assets they hold and increase the amount of risky assets. It has also been suggested, for example by Acharya and Johnson (2007), that because a bank typically has inside information regarding a borrower's credit quality, the bank could use CRT to exploit sellers of credit protection.

Our results show that holding CDS positions without actually holding the equivalent amount of reference entity to the notional can provide an effective hedging tool against a negative shock to instruments unrelated to the actual CDS reference entity. The effect of a significant increase in default risk of a single reference entity has implications for many correlated instruments. Therefore, the required capital gain associated with the holding of a CDS position against default risk typically far outweighs the total value of the reference entities issued bonds. Consequently, holding a broad cross section of naked CDS positions seems to offer an offsetting device against both default and capital risk. In particular, we show that for a log-utility maximising investor over the sample period January 1, 2004 to April 2, 2010 (effectively the longest sample period available for CDS on corporate bonds) the inclusion of a broad set of CDS baskets in a mixed portfolio offsets capital risk by approximately $10 \%$ and increases risk adjusted returns by $28 \%$ per annum.

For all of our simulated investment strategies, the risk adjusted returns are higher when the CDS basket is included. In the case of a simple equally weighting investor, the portfolio with CDS positions outperforms the restricted reference portfolio by nominally $8 \%$, with a corresponding $17 \%$ increase in standard deviation. However, the low correlation between the portfolios results in a beta of only $19 \%$ and a risk adjusted excess return of just over $13 \%$. An additional benefit is that for all strategy types and rebalancing frequencies, the inclusion of the CDS baskets reduces total portfolio turnover even when 46 extra fund baskets are included. This result clearly demonstrates that fund of funds portfolio compositions are more stable when naked CDS positions are included.

The intuition for these findings is that, in the event of a downturn/crisis, equity prices and commodities will decline as pressure is placed on dividends and bankruptcy risk increases. Capital flight to sovereign bonds in reserve currencies, such as the dollar and the yen, and 
the increased risk of default will depress sovereign bond yields and cause the required rate of return on corporate debt to increase. However, the CDS premium will widen on both sovereign and corporate debt and hence naked CDS positions will naturally hedge many other asset classes whilst additionally protecting against default risk. In the case of foreign exchange (FOREX) exposures the naked CDS positions assist in hedging volatility risk as differential impacts on sovereign bond yields will lead to more volatile exchange rates. To exemplify, an investor is compensated for the rise in exchange rate volatility through an increase in returns on the traded CDS positions. Anecdotal evidence suggests that, under adverse market conditions, this volatility feedback results in a rise in spreads on non reserve debt instruments. In the case of an upturn, the inverse is also true. Equity price rises will increase the implied value of assets relative to the value of liabilities, leading to a fall in the probability of default. This in turn, will cause a narrowing of the spread and results in a reduction in the value of CDS positions.

We model the returns on naked CDS positions to capture the day to day variation in the quoted spreads. The profits and losses on these rolled positions are reinvested back into the fund. Thus, in effect it tracks a weighted average of the constituent spreads. Several CDS indices following this approach and a variety of ETFs are available to buy exposure to these indices. Deutsch Bank provides ETFs on a number of short positions tracking the iTraxx five year total return index on the spreads of 125 underlying names. A large number of investment banks provide spread trackers for both long and short positions. In terms of direct implementation of CDS arbitrage opportunities, at present 28 hedge funds out of 8,359 listed on the HedgeFund.net dataset (2009) of North American hedge funds list capital structure arbitrage as a primary or secondary strategy. In addition to these, 138 hedge funds list themselves as fixed income arbitragers. Our analysis restricts itself to addressing the viable returns from the current available CDS positions on the CMA database.

\section{Mark to Market Returns on CDS Positions}

In a CDS transaction the buyer makes periodic payments to the seller and in return receives a payoff if the underlying instrument defaults. Another way of viewing this trans- 
action is that the buyer is acquiring the right to protect the notional value of the underlying asset at a particular payment rate (quoted in basis points per fixed amount of the underlying notional).

In this paper we specifically focus on the mark to market returns on the CDS. It is important to observe that we have deliberately excluded default events as these are impossible to quantify in a portfolio without explicitly identifying the notional amount protected by the position.

We begin our discussion with a simple example to illustrate our approach to CDS trading. We then provide a more complete description of the market and demonstrate why in theory CDS should be a redundant asset in the market. We consider a hedge fund called Pessimist that wishes to speculate on the deterioration in the credit quality of a basket of corporate bonds. The Pessimist fund wishes to invest a fixed amount $V=\$ 1$ Million in this position. For simplicity, we assume that the corporate bonds belong to a sector that contains one hundred named entities issuing corporate debt with very long maturities. As such, these securities are in effect perpetuities. Note that at this stage, we do not consider the required rate of return on the defaultable bonds.

For an equally weighted basket of CDS in these one hundred reference entities, the offered CDS spread is $\kappa_{t}^{\text {offered }}=200$ basis points. Moreover, we assume that the Pessimist fund has private information that suggests that the basket will be trading at $\kappa_{t}^{a s k}=215$ basis points tomorrow. The Pessimist fund buys a notional amount of naked protection on a Notional $_{t}=\$ 50$ Million of the reference name. This is an agreement to pay a quarterly cash flow of Payment Pa $_{t}=\$ 1,000,000$ for the period until the end of the maturity of the CDS, deferred by one quarter. For brevity, suppose that this is a perpetual arrangement with a global risk-free rate of $\beta=2.5 \%$. The present value of this cash flow to the counter-party is approximately $V($ Payment $)=\$ 40$ million .

The Pessimist fund then waits for a period of time - in this case one day - and re-enters the market and sells protection to fully offset the notional naked position. Note that since we assume an interval of one day we do not discount the notional. Additionally, let assume the following. The Pessimist fund was correct in its expectations; the market perception of 
the creditworthiness underlying bonds has deteriorated and the spread is now being asked at $\kappa_{t}^{a s k}=215$ basis points. Assuming also that the time period is reasonably short the trader now enters the market and sells protection on a Notional $_{t+1}=\$ 50$ Million at $\kappa_{t}^{a s k}=215$, which is an agreement to receive Income $=\$ 1,075,000$ at every future quarter from $t+1$. Again for simplicity, this is assumed to be a perpetuity. The value of this income stream is approximately $V($ Income $)=\$ 43$ million. The Pessimist fund can now enter into an exercise of portfolio compression, whereby the matched pair of CDS positions is sold onto to a third party for the difference in $V$ (Income) and $V$ (Payment). We can see that the profit on the exercise is $7.5 \%$, i.e. the difference in investing in a perpetual risk free rate at $2.5 \%$ and the cash flow from the CDS transactions ${ }^{4}$.

In this case no cash has been paid upfront. Hence, the issue to be explored in details is how the $V=\$ 1$ million is invested. To buy the original naked position, a certain amount of collateral needs to be pledged. In such a manner, the fund can show its commitment to honour its contractual obligations. We postulate that for an ongoing contract the hedge fund needs to put on cash in the first quarter similarly to the case of a first payment upfront in a CDS contract. The fund would not wish to enter into a contract to continuously pay the protection leg. Therefore, the pessimist will construct an offsetting position against the calendar spread. By contrast, another fund, the Optimist, expects a contraction in the default spread. As a result, it will enter into the opposing position. In the case of a contraction in the spread to $\kappa_{t}^{a s k}=185$, then the Pessimist fund will not be able to fully offset the outflow from the protection leg of the first transaction and the present value of the back to back transaction will be approximately $V$ (Income $)=\$ 37$ million. Therefore, the rate of return on the initial pledge of $V=\$ 1$ million is $-7.5 \%$. The change in value of each unit of currency thus is proportional to the percentage change in the calendar spread, adjusting for the spread bid and spread offered.

In accounting for the value of this protection, a naked CDS position is booked at mark to market using the same approach as if it were continually offset (albeit from the mid price

\footnotetext{
${ }^{4}$ For the fictional perpetual protection case it is $\frac{N o t i o n a l_{t} \times \kappa_{t}^{a s k}}{\beta}$. Recall that the value of a perpetuity with a coupon of $\$ 1$ million at $2.5 \%$ is $\$ 40$ million.
} 
ignoring the liquidity component). In the event of a default the value of the notional amount protected is released. This is booked as a return over the present value of the promised cash flow. In the case of the Pessimist fund, in the event of a default before the offsetting position is enacted, the accounting profit booked would be $\$ 50$ million $-\$ 1$ million $=\$ 49$ million.

\section{CDS in a Complete Market}

Above we have illustrated an example of a strategy by which CDSs can be used to speculate on the deterioration of creditworthiness of the underlying instruments. Next, we demonstrate how CDSs fit into a complete market of alternative non redundant assets in a more general context. To justify the construction of our nominal returns on a naked CDS contract, we follow an adaptation of the model of Bielecki and Rutkowski (2002) and Bielecki, Jenablanc and Rutkowski (2005). Adopting the notation scheme in Musiela and Rutkowski (2005), we define a random default time $\tau$ on a filtered probability space $(\Omega, \mathcal{G}, \mathbb{Q})$ with jump process $H_{t}=\mathbf{1}_{\tau \leq t}$. The associated jump filtration $\mathbb{H}$ is generated by this default time process. Furthermore, we define an auxiliary stochastic process with filtration $\mathbb{F}$ such that $\mathcal{G}_{t}=\sigma\left(\mathcal{H}_{t}, \mathcal{F}_{t}\right)$ for every $t \in \mathbb{R}_{+}$. For a defaultable claim with promised payoffs $X$, promised dividends $A$ and recovery process $Z$, designated $(X, A, Z, \tau)$ maturing at time $T$, $X$ is an $\mathcal{F}_{T}$ measurable random variable, $A$ is an adapted process with finite variation and filtration in $\mathbb{F}$ and $Z$ is an $\mathbb{F}$-predictable process. The cash flows of a dividend process $D$ maturing at time $T$ is

$$
D_{t}=X \mathbf{1}_{\tau>T} \mathbf{1}_{\tau>\infty}(t)+\int_{0}^{t}\left(1-H_{u}\right) d A_{u}+\int_{0}^{t} Z_{u} d H_{u}
$$

where $\mathbf{1}$ is the indicator function and the premium at $t=0$ is considered, by convention, to be equal to zero. If $A_{t}=-\kappa t$ for some constant $\kappa>0$ then the price of the CDS is the continuously credit default spread or premium. Typically, in a CDS contract the promised payoff, $X$, is zero and $Z$ is determined with reference to a specific recovery rate, for example 
$25 \%$. This is represented by

$$
\int_{0}^{t}\left(1-H_{u}\right) d A_{u}=\int_{0}^{t} \mathbf{1}_{\tau>u} d A_{u}=A_{\tau-} \mathbf{1}_{(\tau \leq t)}+A_{\tau} \mathbf{1}_{(\tau>t)} .
$$

In the event of a default, the remaining promised dividend $A_{t}-A_{t-}$ can be disregarded. Therefore

$$
\int_{0}^{t} Z_{u} d H_{u}=Z_{\min (\tau, t)} \mathbf{1}_{(\tau \leq t)}=Z_{\tau} \mathbf{1}_{(\tau \leq t)} .
$$

For an investor purchasing a defaultable claim at $t, D_{u}-D_{t}, u \in[t, T]$, denotes all cash flows received from the defaultable claim over the time frame $u$. For a risk neutral probability measure $\mathbb{Q}^{*}$, such that $\mathbb{Q}$ is on $\left(\Omega, \mathcal{G}_{t}\right)$, the value of a unit of account $B=S^{k}$ is $B_{t}=$ $\exp \int_{0}^{t} r_{u} d u$ for a continuous interest rate $r_{t}$. The discounted price of an asset $S^{i *}$ is $S_{t}^{i *}=$ $S_{t}^{i} B_{t}^{-1}$, for $i \in 1, \ldots, k-1$ assets with nominal price $S^{i}$ on a filtered probability space $(\Omega, \mathbb{G}, \mathbb{Q})$, where $\mathbb{Q}$ is the observed measure. Note that this is the complete market with arbitrage free pricing described in Karatzas $(1996,2006)$. To this setup we add the traded security of a defaultable claim, with price $S$, by convention considered to be asset zero. We now introduce a process $x \in \mathbb{R}^{k+1}$ measured on $\mathbb{G}$ representing a trading strategy where $x_{t}^{j}$ is the investment weighting of a $j \in 0, \ldots, k$ indexed Arrow-Debreu asset held at time $t$.

\section{Trading Protection In a Complete Market}

We can think of the combination of a fully protected portfolio of a defaultable bond and insurance as a synthetic risk-free rate. A natural question that arises is whether in a fully replicating position is possible to short a default. Brigo and Mercurio (2006) suggest that it is not fully replicating unless a position is constructed by which one can borrow at the defaultable rate and signal the intention to default in a manner that is synchronised with the reference asset. The CDS instrument completes this aspect of the market by allowing the creation of a position that replicates the intention to issue defaultable cash flow with default characteristics identical to the reference defaultable without actually being the reference entity. The information conveyed by the traded price of the CDS is in the form of $\mathcal{G}_{t}$. We 
need to extract this information from the quoted data to understand whether the CDS price is completing the market.

At time $t=0$, one unit of $S$ is purchased at an initial price $S_{0}$ and it is held until expiration T. Following Brigo and Mercurio (2005) and Bielecki, Jeanblanc and Rutkowski (2005), if all the proceeds from the savings account are reinvested in $B$, i.e. $x=\left\{x_{0}=\right.$ $\left.1, x_{k+1}=x^{k}\right\}$, the wealth process $U(x)$ is $U_{t}(x)=S_{t}+x_{t}^{k} B_{t}, \forall t \in[0, T]$. As with a conventional derivative the self financing value of the portfolio is driven by a differential equation, $d U_{t}(x)=d S_{t}+d D_{t}+x_{t}^{k} d B_{t}$. Therefore, for every $t \in[0, T]$, the nominal wealth is

$$
U_{t}(x)-U_{0}(x)=S_{t}-S_{0}+D_{t}+\int_{0}^{t} x_{u}^{k} d B_{u}
$$

and the relative wealth is

$$
U_{t}^{*}(x)=U_{t}^{*}(x)+S_{t}^{*}-S_{t}^{*}+\int_{0}^{t} S_{u}\left(S^{*}\right)^{-1} d D_{u}
$$

Bielecki, Jeanblanc and Rutkowski (2005) derive the ex-dividend continuous price process of the defaultable claim at $t \in[0, T]$ as

$$
S_{t}=B_{t} \mathbb{E}_{Q^{*}}\left(\int_{t}^{T} B_{u}^{-1} d D_{u} \mid \mathcal{G}_{t}\right)
$$

If we now consider a CDS, with spread $\kappa$, this is a defaultable claim $(0, A, Z, \tau)$, where $Z_{t}=\delta(t), A=-\kappa t$ for every $t \in[0, T], \delta:[0, T] \rightarrow \mathbb{R}$ is a càdlàg function that represents the protection payment and $\kappa$ denotes the spread or the premium of a CDS. Bielecki and Rutkowski (2002) provides a simple model of default where the filtration $\mathbb{G}=\mathbb{H}$ is generated by a counting process $H_{t}=\mathbf{1}_{\{\tau \leq t\}}$. For a survival probability function $G=1-F$, where $F$ is a cumulative distribution of the default time $\tau$ under $\mathbb{Q}^{*}$, such that $G(t)>0, \forall t \in[0, T]$. For the purposes of our analysis, suppose that the CDS position is being rolled over every day. Therefore, we assume that the interest $r \rightarrow 0$. From this setup, the ex dividend price 
of the CDS is

$$
S_{t}(\kappa)=\mathbb{E}_{\mathbb{Q}^{*}}\left(\delta(\tau) \mathbf{1}_{\{t<\tau \leq T\}}-\mathbf{1}_{\{t<\tau\}} \kappa(\min (\tau, T)-t) \mid \mathcal{H}_{t}\right)
$$

Hence the ex dividend price at time $t \in[s, T]$, for a CDS instigated at some time $s$ before $t$, is

$$
S_{t}(\kappa)=\mathbf{1}_{\{t<\tau\}} \frac{1}{G(t)}\left(-\int_{t}^{T} \delta(u) d G(u)-\kappa \int_{t}^{T} G(u) d u\right)
$$

We now present an important definition for the nominal return calculation on a CDS contract with changing spread. The spread $\kappa(s, T)$ of a CDS at the inception of the contract is determined by $S_{s}(\kappa(s, T))=0$. For the $T$ maturity market spread the value of the contract is the solution to

$$
\int_{s}^{T} \delta(u) d G(u)+\kappa(s, T) \int_{s}^{T} G(u) d u=0
$$

and therefore for a traded CDS for $s \in[0, T]$, the spread is

$$
\kappa(s, T)=\int_{s}^{T} \delta(u) d G(u)\left(\int_{s}^{T} G(u) d u\right)^{-1}
$$

The difference $v(t, s)=\kappa(t)-\kappa(s)$ represents the calendar spread between $s$ and $t$ and for a rolled over position such that $t-s$ is a short time period where $v(t, s)$ represents the nominal return on the naked-only position. In the next section, we provide an alternative implementation of the problem under investigation by letting the portfolio weights rebalance across a very broad set of assets. We define a vector process of dollar positions (normalised as weights) $x(t)=\left[x^{\prime}(t)_{C D S}, x^{\prime}(t)_{A l t}\right]^{\prime}$ for the CDS and alternative asset funds.

\section{Trading Strategies and Unit of Account}

Consider a quoted naked CDS spread at time $t$ with offered spread $\kappa_{t}^{\text {offered }}$, spread ask $\kappa_{t}^{a s k}$ and transacted spread $\kappa_{t}^{\text {trans }}$. The contract inception is at $t_{0}<t<T$ and the discounted value of the outflows is given by $\pi\left(\kappa_{i, t}^{\text {trans }}, V_{t}, T-t\right.$, ) for protection held, where $V_{t}$ is the 
notional amount under protection. We now consider a fund that purchases protection at $t$ and then sells protection at $t+\Delta t$. This generates a cash flow with expected value

$$
\tilde{\Lambda}_{i, t}=B_{\Delta t}^{-1}\left(\pi_{t+\Delta t}\left(\kappa_{i, t}^{\text {trans }}, B_{\Delta t}^{-1} V_{t}, T-t, B_{t}\right)-\pi_{t}\left(\kappa_{i, t}^{\text {trans }}, V_{t}, T-t, B_{t}\right)\right)
$$

The period $\Delta t$ is the short exposure time on the CDS position. Suppose this a very short period, say a day, and assuming no default event, the value of the cash flow is approximated by the spread bid to spread offered in the market. Then if $B_{\Delta t}^{-1} \rightarrow 1$ and the variation is driven by an affine transformation of $\kappa_{i, t}^{\text {trans }}$, the price at which counter-parties are willing to buy or sell protection in the market is equal to

$$
\tilde{\Lambda}_{i, t} \approx \kappa_{t+\Delta t}^{\text {offered }}-\kappa_{t}^{\text {ask }}
$$

We term this the realized calendar spread. The trader can leverage the position $\tilde{\Lambda}_{i, t}$ by a factor $V_{t}$. The initial trade is of course costless. However, with the offset position, the variation in $\kappa_{t+\Delta t}^{\text {offered }} \mid \kappa_{t}^{\text {ask }}, \kappa_{t}^{\text {offered }}, \kappa_{t}^{\text {trans }}$ provides the account payoff risk.

\section{Empirical Methodology and Data}

Conceptually, traded protection instruments such as CDSs have a particular payoff structure that in some way could be replicated by combinations of other instruments within a large market of alternatives. In this section, our aim is to determine whether CDS positions, aggregated as fund baskets, have a replicable return and risk diversification profile relative to a large set of alternative assets. The short available sample is generally unsuitable for more traditional long run covariance/regression analysis such as the approach suggested in Campbell, Serfaty-De-Medeiros and Viciera (2010). Consequently, we restrict our approach to an analysis of portfolio returns and portfolio correlation structures, via bootstrap resampling. Following the theoretical framework presented in $\S(3)$ whereby prices are set in the risk neutral universe, we operationalise our empirical approach from the viewpoint of a risk averse fund management. This reduces the portfolio problem to a smooth mean-variance 
optimisation procedure and this is critical when dealing with such a large assets universe.

Alternative approaches to identifying the correct benchmark return would be to derive the specific replicating portfolio specifically for each individual contract from the PDE suggested in $\S(3)$. The drawback here is identical to the issue faced when analysing the correct futures hedge. It is impractical to precisely match individual spot and derivatives contracts. Therefore, the replicating hedge is not easily identifiable. We choose to benchmark our CDS positions against restricted portfolios using a historical mean-variance optimisation approach, in the spirit of Kroner and Sultan (1993), but incorporating a randomised robustness check. In other words we view the problem as a risk averse mean variance optimizer and if substantial and excess returns are observed when CDS positions are included in the portfolio relative to a restricted benchmark then we conclude that the portfolio cannot be replicating in this manner.

We also report the levels of skewness and kurtosis in the distribution of correlations within the portfolios. There is an extensive contemporary literature on the inclusion of higher order (> 2) moments and co-moments, see for instance Jondeau and Rockinger (2006) and Martellini and Ziemann (2010). The major issue here is in the complete market derivation. Higher order terms in the taylor series are therefore needed to correctly identify the underlying risk neutral probability process. We should note that the under most conventional preference sets the magnitudes of the third and fourth moments would need to be very large in order to substantially adjust the portfolio weights as the adjustment decays at $k !^{-1}$, for the $k^{t h}$ moment. There is, however, little evidence for this in the unconditional descriptive statistics.

The general orientation of the optimisation problem is from the view of the second order expansion of a smooth at least twice differentiable utility function of wealth, $u\left(w_{t}\right)$, whereby the expected utility at a terminal time period $T$, is given by

$$
\mathbb{E}\left(u\left(w_{T} ; \theta\right)\right)=u\left(w_{0} ; \theta\right)+u^{\prime}\left(w_{0} ; \theta\right) \mathbb{E}\left(w_{t}-w_{0}\right)+\frac{1}{2} u^{\prime \prime}\left(w_{0} ; \theta\right) \mathbb{E}\left(w_{t}-w_{0}\right)^{2}
$$


where the first two moments of the wealth generating process are

$$
\begin{aligned}
\mathbb{E}\left(w_{t}-w_{0}\right) & =w_{0} \exp \left(\int_{0}^{t} x^{\prime}(t) \mathbb{E}(r(t)) d t\right) \\
\mathbb{E}\left(w_{t}-w_{0}\right)^{2} & =w_{0}^{2} \exp \left(\int_{0}^{t} x^{\prime}(t) \Sigma(t) x(t) d t\right)
\end{aligned}
$$

The optimisation problem is of the form $\max _{x(t)} \mathbb{E}\left(u\left(w_{T} ; \theta\right)\right)$. Where $\theta$ is a vector of utility function parameters, $x(t)$ is the vector of portfolio weights, $r(t)$ is the vector portfolio returns process and $\Sigma(t)$ is a time varying variance covariance matrix. The expected utility maximisation problem can be orientated to maximise directly 14 . Or by constraining the problem by setting a target level of risk, which is indeed a common hedge fund strategy.

We utilise three strategies. First, we impose a power utility with unit risk aversion. Thus, the utility function simplifies to $u\left(w_{t} ; \theta\right)=\log \left(w_{t}\right)$ and the expected utility maximisation is

$$
\max _{x(t)} \int_{0}^{t} x^{\prime}(t) \mathbb{E}(r(t)) d t-\frac{1}{2} \int_{0}^{t} x^{\prime}(t) \Sigma(t) x(t) d t
$$

For a target risk level $\sigma^{2}$, the optimisation is

$$
\max _{x(t)} \mathbb{E}\left(u\left(w_{T} ; \theta\right)\right) \mid \int_{0}^{t} x^{\prime}(t) \Sigma(t) x(t) d t=\sigma^{2}
$$

And finally for a target minimum variance level

$$
\max _{x(t)} \mathbb{E}\left(u\left(w_{T} ; \theta\right)\right) \mid \min \int_{0}^{t} x^{\prime}(t) \Sigma(t) x(t) d t
$$

The simple objective here is to randomly impose asset class restrictions and then run the portfolios recursively over the large cross section of assets and compare this to the systematic restriction.

Having set the investor portfolio optimisation conditions, we construct broad highly di- 
versified portfolios consisting of funds drawn from six asset classes: CDS, equity, corporate bonds, sovereign bonds, FOREX and commodities. These asset classes are further decomposed into sub-baskets of simulated funds that consist of a very large number of underlying positions. The components of these funds are weighted by asset class convention: equal weights for the CDS baskets, capitalization weights for equity baskets, equal weights for bonds, trade weights for FOREX and production weights for commodities. The full list of 255 funds is presented in Table B.6. We define 'broad' as an individual fund that invests in more than twelve underlying instruments. Our approach simulates a set of dollar funds investing in these baskets and a fund of funds that optimises across these individual funds.

To analyse the return structure of CDS positions within this large cross section of alternative assets, we employ a large scale ex-ante back tested optimisation, whereby we construct simple rolling mean variance forecasts for the broad cross section of assets that are optimized recursively. We then apply systematic and random restrictions on various assets and re-apply the back testing on the restricted set. For each portfolio, we record the daily returns and variances as well as the internal correlation structures. We then compare the properties of the randomly restricted portfolios to the systematic restrictions.

Our empirical strategy is to consider a single class of CDS positions for a given sector consisting of equally weighted naked CDS positions for all available maturities. For a change in the spread $\Delta \kappa_{t}$, we compute a nominal change in the value of a single unit position following the definitions set out in Equations 7 to 10. For a back to back trade over $t+\Delta t$, where we assume $\Delta t$ is one day, the fund is adjusted on a daily basis to capture the return on the changing spread. For simplicity, we assume that the overnight unit of account is stored as cash and therefore the interest rate is zero. This trading strategy in CDS positions results in a large number of outstanding contracts. At regular intervals, hedge funds and other investment vehicles undertake a process of 'portfolio compression', whereby the notional size and number of outstanding contracts are reduced by terminating contracts and then replacing them with a smaller number of trades with the same payoff structure.

We equally weight 2,846 CDS positions into 51 sector funds for the US, UK, EMU and Japan. For the CDS and bond positions our approach is to create macro indices, replicating 
a hedge fund providing investment funds in broad swathes of assets. To achieve this for even a modest time period we are restricted to corporate debt for mature industrialised countries. Thomson-Reuters through the TickHistory and DataStream services provide intra-day and end of day aggregates for CDS positions on corporate debt. Information is provided on credit events, maturities of underlying instruments and spread bid and spread ask, as well as information about the issuer.

All available corporate CDS positions for US, UK, EMU and Japanese corporate bonds traded for the period from January 1, 2004 to April 2, 2010 are included in the study. Note that certain CDS position data is available from January 1, 2003. However, the early spreads exhibit stale pricing effects. Hence, our sample begins on January 1, 2004. Additionally, we simulate ETFs that invest in all US, UK, EMU and Japanese listed equities and construct 40 funds defined by country and sector. All available US, UK, EMU and Japanese corporate bonds are grouped by country and sector, into 60 funds. All available US, UK, EMU and Japanese sovereign bond yields for 2, 3, 5, 7, 10, 15, 20 and 30 year maturities are divided into 30 macro funds, classified by country and maturity. To include foreign exchange exposures, we use trade weighted indices for 46 currencies and we also include 28 broad commodity indices consisting of multiple futures positions. These instruments are then placed into 255 funds and weighted in the fund of fund portfolio optimisation. When bid-ask information is not available for certain days, we utilise the average bid-ask ratios to adjust returns for transactions costs.

Table B.6 describes each asset class $^{5}$. To derive returns on these fund baskets, we adopt the following approach. First, CDS returns are equally weighted and quoted as spread bid to spread ask. Second, equities are indexed in terms of total return, adjusted for dividends, the bid-ask spread and weighted by market capitalization. Third, corporate and sovereign bonds are equally weighted and indexed as total returns, with all gross coupons reinvested. Fourth, currency baskets are computed in returns at trade weights. Finally, commodities

\footnotetext{
${ }^{5}$ We gratefully acknowledge the assistance of Thomson Reuters and CMA in assisting in building the instrument baskets. Thomson Reuters DataStream CMA currently provides sector level basket data using the cross section of assets available in the CMA database and we use this list to build our CDS sector funds.
} 
indices are computed from production weighted portfolios, adjusted for the bid-ask spread. All instruments returns are in US dollars. Table 1 provides summary information for our total return methodologies and for all the aggregated underlying positions and funds by asset class.

Table 1: Summary of fund positions and valuations

The CDS, equity and corporate and sovereign bond positions and returns are computed directly from underlying individual instruments data provided by Thomson-Reuters. We use third party indices for foreign exchange (FOREX) and commodities positions. The specific calculations used are summarised in $\S \S$ Appendix A.

*FOREX funds are supposed to track the J.P. Morgan Broad Trade Weighted Index. These indices are designed to be tracked by ETFs and consist of a basket of multiple forward rates, trade weighted over a basket of currencies. Source: J.P. Morgan Broad Trade Weighted Indices Methodology 2010.

**Commodities funds are supposed to track the Standard and Poor's - Goldman Sachs commodity index (S\&P GSCI). This is a production weighted index of liquid futures positions over multiple maturities. These indices track the complete 12 month futures curve and are computed over 30,000 individual contracts per annum. Source: S\&P GSCI Index Methodology 2010. Several ETFs are available to track these indices. In total, we utilise 42,559 individual data series to construct 255 funds for which we can compute nominal returns. Nevertheless, the total number of actual underlying positions is in excess of 100,000 depending on the inclusion criteria for the FOREX and commodities baskets.

\begin{tabular}{lrrrr}
\hline \hline Asset Class & Positions & Fund Baskets & Daily Obs. & $\begin{array}{r}\text { Total Obs. } \\
\text { (Bid, Ask, Transacted) }\end{array}$ \\
CDS & & & & 248,013 \\
Equities & 2,846 & 51 & 1,621 & 194,520 \\
Corporate Bonds & 25,922 & 40 & 1,621 & 291,780 \\
Sovereign Bonds & 10,545 & 60 & 1,621 & 145,890 \\
FOREX* & 2,886 & 30 & 1,621 & 223,698 \\
Commodities** & 46 & 46 & 1,621 & 136,164 \\
\hline Total & 314 & 28 & 1,621 & $1,240,065$
\end{tabular}

Our sample period starts on January 1, 2004 and runs daily until April 2, 2010. This yields 1,621 trading days of data. We utilise the first 100 days of the sample to initialise the econometric analysis of the expected mean and variance for the portfolio weights optimisation. Our portfolio optimisations are assumed to be dynamic over the period, rebalancing over a time horizon of $s$ days at set periods, $t_{1}, t_{2}, \ldots, t_{3}$. 


\section{Portfolio Construction}

We define a vector of nominal daily returns on CDS positions and alternative asset positions as being $r_{t}=\left[r_{C D S, t}^{\prime}, r_{A l t, t}^{\prime}\right]^{\prime}$, where $r_{A l t, t}$ is the collection of non CDS assets

$$
r_{A l t, t}=\left[r_{\text {Equity }, t}^{\prime}, r_{\text {FOREX }, t}^{\prime}, r_{\text {Corp }, t}^{\prime}, r_{\text {Sov }, t}^{\prime}, r_{\text {Comms }, t}^{\prime}\right]^{\prime}
$$

We refer to this as the reference portfolio. The time $t$ expected returns, conditional on the current information set $\Omega_{t}$, is therefore $\mathbb{E}_{t}\left(r_{t} \mid \Omega_{t}\right)=\mu_{t}$. The time $t$ residuals are $r_{t}-\mu_{t}=u_{t}$ and hence the time $t$ conditional covariance matrix can be written as

$$
\Sigma_{t \mid t=1, \ldots, t=t-1}=\mathbb{E}_{t}\left(\left(r_{t}-\mu_{t}\right)\left(r_{t}-\mu_{t}\right)^{\prime} \mid \Omega_{t}\right)
$$

For the three rebalancing regimes, weekly, monthly and quarterly for a set of portfolio weights $x_{t}$, such that the realized portfolio returns are $r_{p, t}=x_{t}^{\prime} r_{t}$, the expected portfolio returns and portfolio conditional standard deviations are defined respectively as

$$
\mathbb{E}_{t}\left(r_{p, t}\right)=x^{\prime}{ }_{t} \mu_{t}, \quad \sigma_{p}=\left(x^{\prime}{ }_{t} \Sigma_{t} x_{t}\right)^{\frac{1}{2}}
$$

We confine our analysis to three investor types with corresponding portfolio optimisation problems. First, the minimum variance targeting portfolio is rebalances using the following objective function

$$
\sigma_{\min , p} \triangleq \min _{x_{t}}\left(x^{\prime}{ }_{t} \Sigma_{t} x_{t}\right)^{\frac{1}{2}}
$$

where $x_{\min , t}$ are the target weights for the minimum variance portfolio. We follow standard hedge fund covenants and set a $6 \%$ concentration limit in each of the 255 funds. The second investor type targets a logarithmic utility function and as such seeks to maximise the following

$$
\mathbb{E}_{t}\left(u\left(r_{t}\right) \mid x_{u t i l, t}\right)=\max _{x_{t}}\left(x^{\prime}{ }_{t} \mu_{t}-\frac{1}{2} x^{\prime}{ }_{t} \Sigma_{t} x_{t}\right)
$$


The final investor type targets the maximum return subject to a particular annualised standard deviation $\bar{\sigma}_{p}$. The objective function is therefore

$$
\mathbb{E}_{t}\left(r_{p, t} \mid x_{r i s k, t}\right) \triangleq \max _{x_{t}} x_{t}^{\prime} \mu_{t}, \text { subject to, }\left(x^{\prime}{ }_{t} \Sigma_{t} x_{t}\right)^{\frac{1}{2}}=\bar{\sigma}_{p}
$$

In addition to the actively rebalanced portfolios, we construct an equally weighted benchmark portfolio $r_{e q}$ as an alternative reference entity.

$\begin{array}{lll}\text { Optimisation Criterion } & \text { Reference Portfolio Designation } & \text { Test Portfolio Designation } \\ \text { minimum variance } & r_{p, \text { minex }} & r_{p, \text { min }} \\ \text { logarithmic utility } & r_{p, \text { utilex }} & r_{p, \text { util }} \\ \text { variance targeting } & r_{p, \text { riskex }} & r_{p, \text { risk }} \\ \text { equally weighted } & r_{p, \text { equalex }} & r_{p \text {,equal }}\end{array}$

\section{Robust Covariance Estimation}

Kyj, Ostdiek and Ensor (2010) introduce a shrinkage estimator on high frequency data and we follow strictly this approach to ensure that the portfolio weights are derived from a well conditioned matrix. The basic conditional covariance matrix is constructed from an exponentially weighted moving average model with bandwidth $\alpha$ and lagged kernel weighting $h_{i}=(1-\alpha)^{i}, \forall i \in\{1, \ldots, l\}$ to compute the expected returns and covariances. The number of lags containing the $\lambda=99 \%$ mass is $l=\frac{\log (1-\lambda)}{\log (1-\alpha)}$. The optimal bandwidth parameter for the mean model is computed via the minimum mean squared error. A further important attribute of our analysis is that we set the expected return $\mu_{t}=\sum_{i=1}^{l} h_{i} r_{t-i}$ and then collect the sequence of past abnormal returns $u_{t-1}^{\prime}, u_{t-2}^{\prime}, \ldots, u_{t-u}^{\prime}$. Due to the high dimensionality of the system, the conditioning of the covariance matrix is an issue. Therefore, we optimise the covariance estimation over the bandwidth parameter $h$.

$$
\Sigma_{t}=\sum_{i=1}^{l} h_{i} u_{t-i} u_{t-i}^{\prime}
$$


The $p$ conditioning number is calculated as follows

$$
\varsigma_{t}=\left\|\Sigma_{t}\right\|_{p}\left\|\Sigma_{t}^{-1}\right\|_{p}
$$

Values of $\varsigma_{p, t}$ near 1 indicate a well conditioned matrix. Poorly conditioned matrices often have multiple non convergent solutions. To overcome this issue, we propose the following optimisation procedure. First, we adjust the bandwidth parameter $h$ and hence the $u_{t-i}, \forall i \in$ $\{1, \ldots, l\}$ to generate a set of matrices $U_{j, t}, \forall j \in\{1, \ldots, J\}$. Next, for each matrix we compute the corresponding covariance matrix $\Sigma_{i, t}$ and conditioning number $\varsigma_{i, t}$. Finally, we identify a point at which the reduction in the conditioning number flattens.

\section{Portfolio Performance and Correlation Measures}

For each portfolio selection strategy, we construct a reference portfolio excluding the CDS baskets. For each portfolio return series, we then utilise a set of conventional portfolio performance tests to compare the relative performance of the test versus the reference portfolios.

\section{Total Return and Risk Adjusted Evaluation}

Consider the observed returns of the reference portfolio $r_{r e f, t}$ and test portfolio $r_{t e s t, t}$. The mean return is computed by $\mu_{\text {ref }}=T^{-1} \sum_{t=1}^{T} r_{r e f, t}$ and $\mu_{t e s t}=T^{-1} \sum_{t=1}^{T} r_{\text {test }, t}$ and the heteroskedasticity and autocorrelation consistent (HAC) variance for each portfolio is determined by $\sigma_{r e f}^{2}=h^{\prime} \Gamma_{r e f} h$ and $\sigma_{\text {test }}^{2}=h^{\prime} \Gamma_{\text {test }} h$, where $\Gamma$ is the autocovariance matrix and $h$ is the vector of kernel weights with bandwidth parameter $\lambda$. Setting $\rho$ to be the unconditional correlation between the reference and test portfolios we can assume the following: $\operatorname{cov}\left(r_{\text {ref }}, r_{\text {test }}\right)=\sigma_{\text {test }, \text { ref }}=\rho \sigma_{\text {ref }} \sigma_{\text {test }}$ and $\beta_{\text {test }, \text { ref }}=\frac{\sigma_{\text {test,ref }}}{\sigma_{\text {ref }}^{2}}=\rho \sigma_{\text {ref }}^{-1} \sigma_{\text {test }}$. We can now set out the conventional portfolio evaluation measures in terms of our notation as

$$
\Lambda_{n o r m 1}=\mu_{\text {test }}-\beta_{\text {test }, \text { ref }} \mu_{\text {ref }}, \quad \Lambda_{\text {norm } 2}=\frac{\sigma_{\text {test }}}{\sigma_{\text {ref }}}
$$


The excess return $\Lambda_{\text {norm1 }}$ captures the risk adjusted differences in expected and realized returns for the test and reference portfolios. The volatility ratio $\Lambda_{\text {norm } 2}$ simply measures the difference between the standard deviations of the test and reference portfolios.

\section{Average Correlation Evaluation}

In the previous section, we have presented performance evaluation tests for the aggregate returns on the reference and test portfolios. We now introduce an alternative and useful measure that focuses on the weighted and unweighted correlations of the reference baskets within the portfolio structure. The test portfolio covariance and correlation matrices are partitioned relative to the reference portfolio as follows

$$
\Sigma_{t}=\left[\begin{array}{ll}
\Sigma_{C D S, t} & \Sigma_{r e f, C D S, t} \\
\Sigma_{r e f, C D S, t} & \Sigma_{r e f, t}
\end{array}\right], \quad R_{t}=\left[\begin{array}{ll}
R_{C D S, t} & R_{r e f, C D S, t} \\
R_{r e f, C D S, t} & R_{r e f, t}
\end{array}\right]
$$

where $\Sigma_{r e f, C D S, t}$ and $R_{r e f, C D S, t}$ are the canonical covariance and correlations between the CDS portfolio and the reference portfolio, respectively. Setting the weighting matrix for the reference and test portfolios as $X_{r e f, t}=x_{r e f, t} x_{r e f, t}^{\prime}$ and $X_{t e s t, t}=x_{t e s t, t} x^{\prime}{ }_{t e s t, t}$, where for the reference portfolio $x_{r e f, t}^{\prime}=\left[0^{\prime}, x^{\prime}{ }_{e x C D S}\right]^{\prime}$, we can then develop a weighted average measure of the correlations as follows

$$
\begin{aligned}
& \xi_{\text {ref }, t}=e^{\prime} \text { ivech }\left(\left(R_{t}-I\right) \circ X_{\text {ref }, t}\right) \\
& \xi_{\text {test }, t}=e^{\prime} \text { ivech }\left(\left(R_{t}-I\right) \circ X_{\text {test }, t}\right)
\end{aligned}
$$

where $I$ is an identity matrix of size $n_{\text {ref }}$ and $n_{\text {test }}$ respectively, $\circ$ is the Hadamard product, $n_{r e f}$ is the number of assets in the reference portfolio and $n_{\text {test }}$ is the number of elements in the test portfolio. The ivech operator stacks the elements of the upper triangular part of the matrix in a vector. Hence, the weighted correlation test statistic is

$$
\Lambda_{\text {corr }}=-T^{-1} \sum_{t=1}^{T} \xi_{\text {ref }, t}-\xi_{\text {test }, t}
$$


For inference, we use bootstrap resampling to compute the empirical distribution of $\Lambda_{\text {norm } 1}$, $\Lambda_{\text {norm } 2}$ and $\lambda_{\text {corr }}$. The null hypothesis in this case that average correlation within each portfolio at each time step is equal, $H_{0}: \xi_{\text {ref,t }}=\xi_{\text {test }, t}{ }^{6}$.

This proceeds by resampling with replacement the vector of time observations $t=$ $1, \ldots, T$ and computing the empirical 1, 5 and $10 \%$ significance bounds. For comparison, we take the following approach. First, we recompute the test and reference portfolios with each asset class systematically restricted, i.e. $x_{r e f, t}^{\prime}=\left[0^{\prime}, x^{\prime}{ }_{e x A l t}\right]^{\prime}$, Alt $\in\{$ Equity, FOREX,Corp, Sov, Comms $\}$ and compute $\Lambda_{\text {corr }}$ for each restriction. To ensure robustness, we then repeatedly and randomly restrict $m$ assets where $m \in\{1, \ldots, n\}$, which are randomly sampled from a uniform distribution. We can test whether the change in correlation structure from a systematic restriction of a given asset class is significantly different from a random restriction. This is accomplished by repeating the random restrictions $N$ times and then sorting the resultant $\Lambda_{\text {corr }}$ to compute the appropriate critical bounds. The procedure originates from the method suggested by Muirhead (1981). However, our approach differs from Muirhead (1981) in that we test for the differential correlation between two alternative average measures rather than testing the average correlation against zero. Finally, it is important also to note that we bootstrap resample the correlation test statistics for significance utilising a modification of the correlation bootstrap, as suggested in Hatemi and Roca (2006). Evidence for the stability of the test statistics from Monte-Carlo simulations are available from the authors.

\section{Empirical Results}

Tables 2 and 3 present the descriptive statistics and correlations for the six portfolios aggregating by equally weighted asset classes (designated as the naive portfolios). The first striking result that we observe is the size of the comparative average annualised returns

\footnotetext{
${ }^{6}$ The distribution of this statistic under assumption that the DGP is normal with covariance matrix drawn from a Wishart distribution $\tilde{\Sigma}_{t} \sim \mathcal{W}\left(p, q, \bar{\Sigma}_{t}\right)$, where $p$ and $q$ are row and column-wise degrees of freedom and $\bar{\Sigma}_{t}$ is the asymptotic long run covariance matrix, is relatively tractable to compute via MonteCarlo simulation. However, we assume that there are various contaminants in the data and use a resampling approach to determine sample critical bounds.
} 
for each asset class. The CDS baskets are averaging 35.7\% per annum over the sample period. Overall this finding is in line with anecdotal evidence for the very large speculative returns to investments in naked CDS positions. The equity and commodities portfolios reveal an average annualised aggregate return of $8.6 \%$ and $6.8 \%$, respectively. Note that these aggregate measures, grouped by asset classes, are useful guidelines in assessing the relative performance of the alternative actively managed portfolios.

The linear correlation between the naive CDS and equity portfolios is $-12.4 \%$. Importantly, this average correlation is stable over the sample period. Accordingly, capital arbitrage strategies are able to generate significant returns by exploiting miss-pricing relative to this negative correlation. As expected, the returns on the CDS portfolios are positively correlated with corporate and sovereign bond portfolios, but are significantly negatively correlated with the FOREX and commodities portfolios. This measurement is economically important in the sense that the row-wise aggregate correlation with the other five asset classes is -0.72 , i.e. an average of $-14.4 \%$ across asset classes. Therefore, the long run correlations are globally negative. Remarkably, this evidence suggests that overall investments in naked CDS positions do hedge capital risk (as well as default risk) across a wide variety of assets.

\section{Risk Adjusted Returns versus Reference Portfolio}

Table 4 reports the results across the ten portfolios for the comparative risk-adjusted returns set out in test $\lambda_{\text {norm } 1}$. Table 4 shows that the risk-adjusted returns for every strategy and rebalancing frequency are higher for the test portfolios. Furthermore, only three portfolios exhibit a standard deviation ratio greater than one. The first is the equally weighted portfolio whilst the other two are the weekly and quarterly variance targeting portfolios, which appear unable to accurately target a particular risk level. Additionally, we bootstrap resample the results reported in column five of Table 4 and find that the positive excess returns are significant at $1 \%$ for all the portfolio strategies and rebalancing frequencies. The uniformity of improvement in the portfolios is remarkable and unambiguous. The inclusion of the CDS positions in actively managed portfolios yields substantially higher risk-adjusted 
returns. More importantly, for higher risk strategies, the return to risk of investing in CDS positions increases. The log-utility portfolios exhibit a $31.32 \%, 28.00 \%$ and $24.45 \%$ annualised risk adjusted excess return over the reference portfolio.

\section{Weighted Correlations Test versus Reference Portfolio}

Table 5 reports the results for the differences in weighted average correlations between the reference and test portfolios. The first column presents the difference in weighted average correlations when the weights on the CDS funds are restricted to zero, the second column for equity and so on. The table is divided in three sections, namely the weighted difference in correlations over the whole sample and for two partitioned sub samples over the periods January 1, 2004 to July 31, 2007 and August 1, 2007 to April 2, 2010. The final three columns present resampling results for random imposed restrictions on different funds.

This allows comparison to check whether the difference in weighted correlations between the test and restricted reference portfolios is statistically dissimilar from a randomly imposed restriction. The results also show that for the whole sample and both sub samples, the weighted correlation of the portfolios is lower when the naked CDS positions are included (i.e. benefits the most from the relaxation of the portfolio weights restriction). The reduction in weighted correlation within the portfolio is greatest for the higher risk portfolios, indicating that funds of funds targeting higher expected returns can benefit substantially from allowing the inclusion of the naked CDS funds. The difference in weighted correlations for a restriction on sovereign and corporate bond portfolios are also significantly different from a random restriction. Nevertheless, the magnitudes are substantially smaller.

The results of the weighted correlation test indicate that the inclusion of the CDS funds reduces, on average, correlation, across rebalancing frequencies, by approximately $7 \%$ for the minimum variance portfolio, $6 \%$ for the log utility portfolio and $1.5 \%$ for the variance targeting portfolio. For the first two strategies, the inclusion of CDS funds produces statistically significant reductions in the weighted correlations within the portfolio. This result clearly indicates that utilising naked CDS positions in basic mean variance strategies with standard objective functions does improve the diversification of risk within the portfolio. Bootstrap resampling suggests that this result is significant at 10\%, 5\%and $1 \%$ significance. 


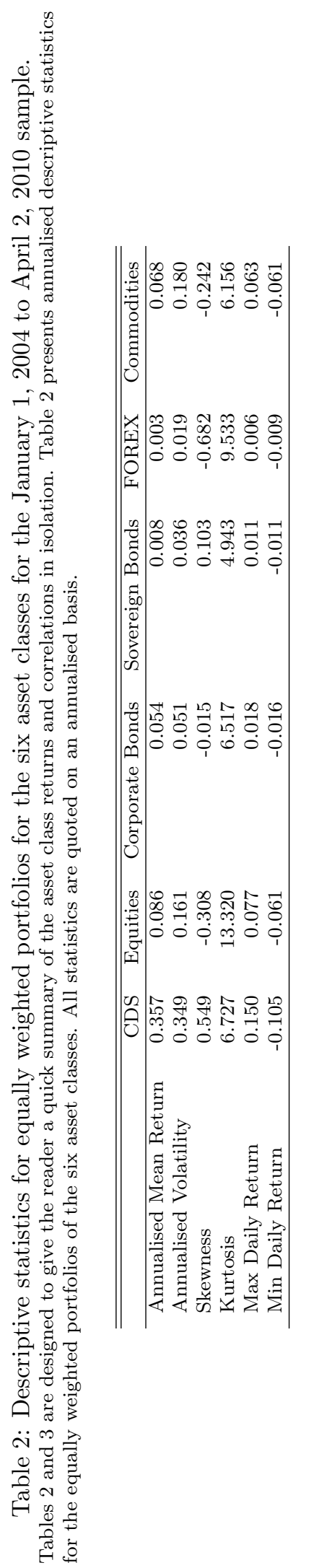

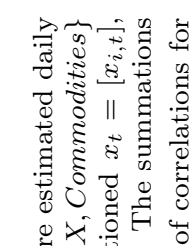

元这.

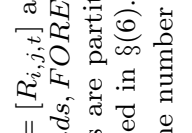

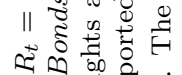

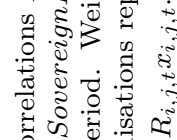

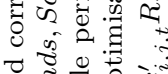

चี हैं

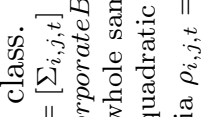

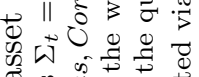

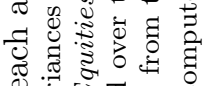

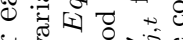

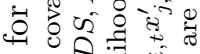

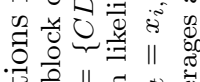

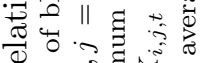

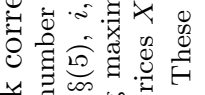

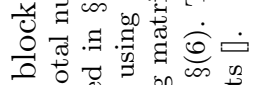

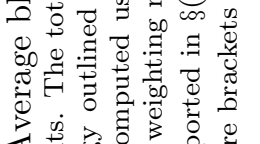

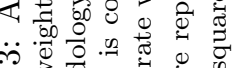

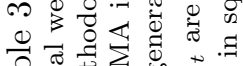

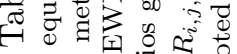

घี

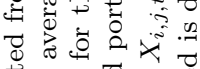

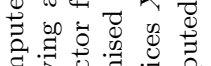

हूँ

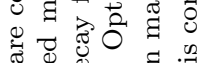

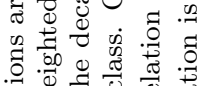

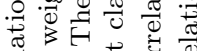

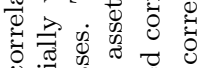

ن.

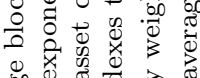

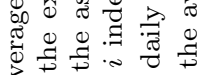

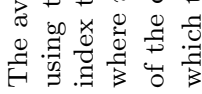

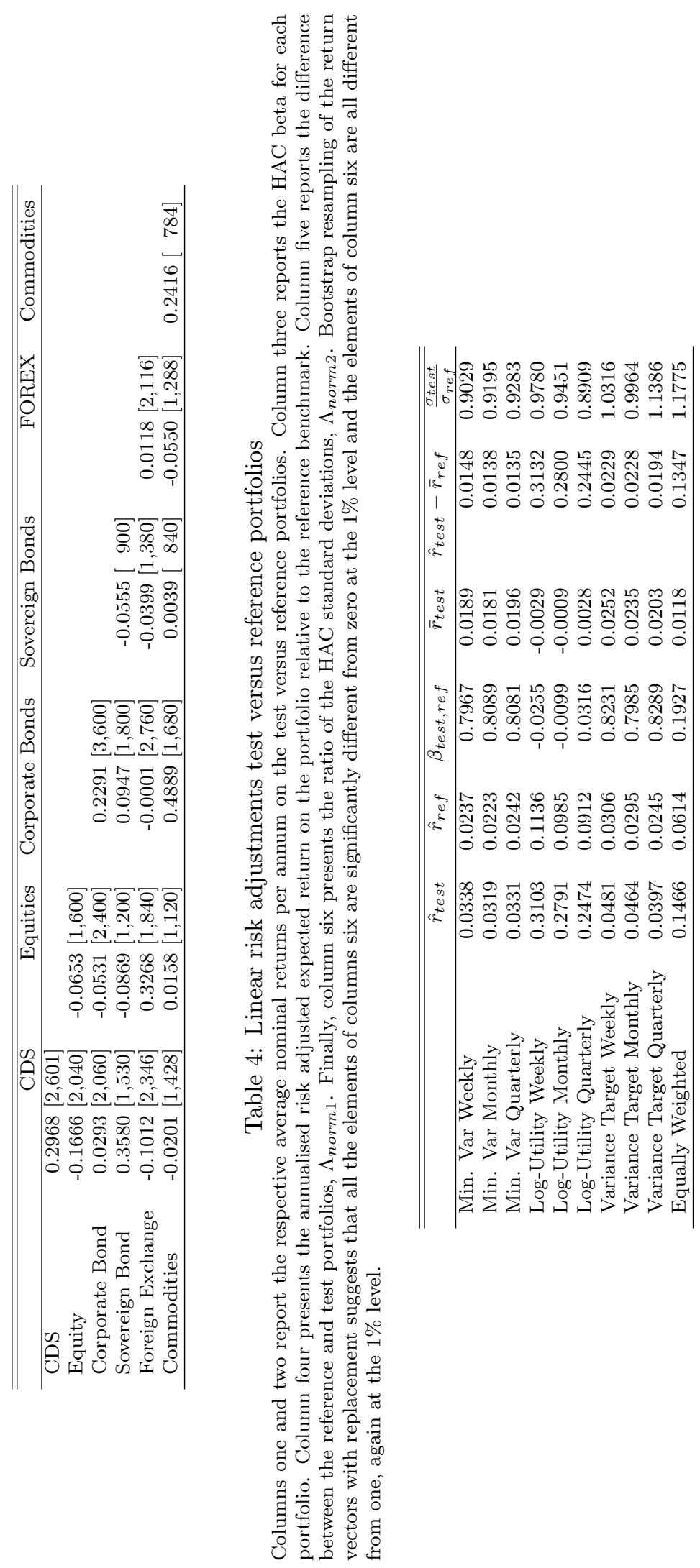




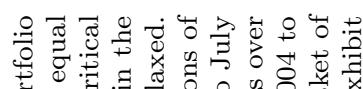

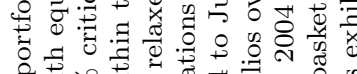

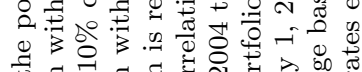
겨의

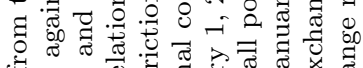

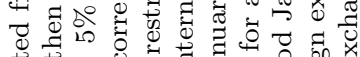
웅

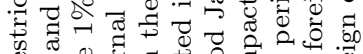

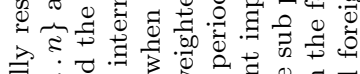

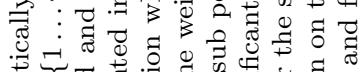
n)

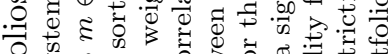

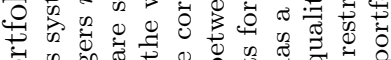

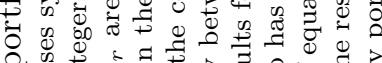

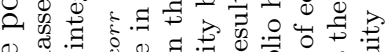
o

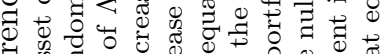

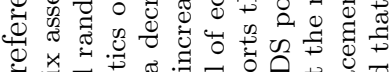

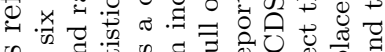
on 0 . : क

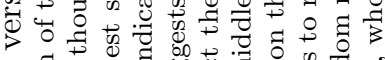

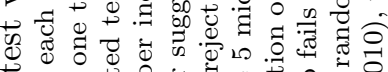
$\ddot{4}$ 击

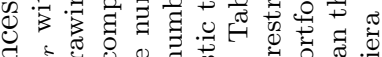
च

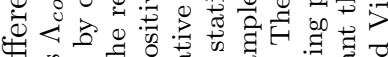
告学

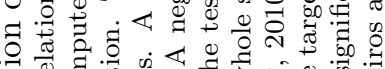

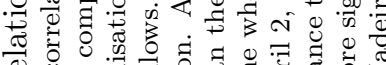
의

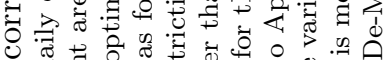
000 T.

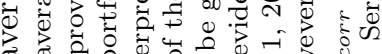

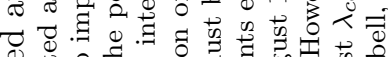

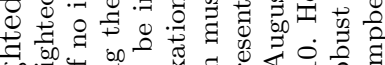

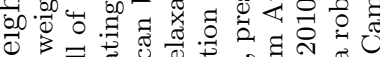

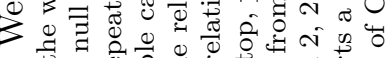

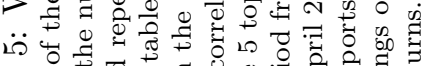

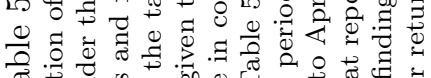

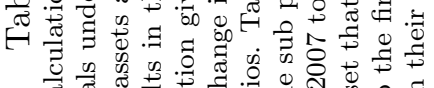
造

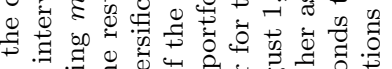

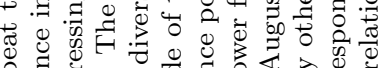

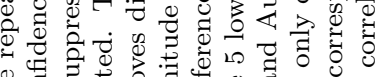

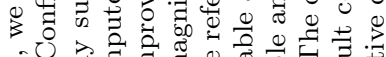
O

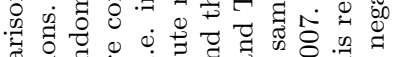

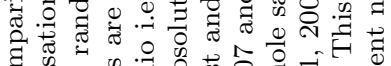
列.

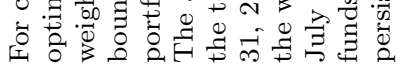

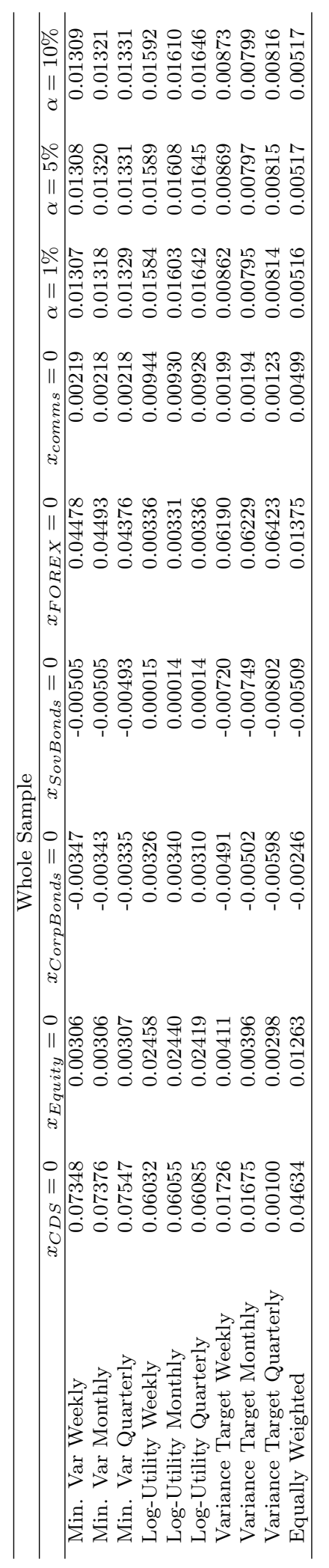

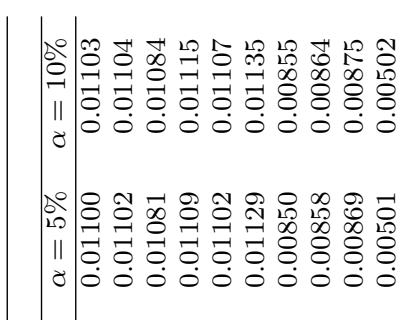

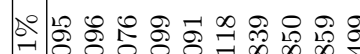

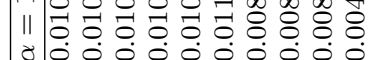

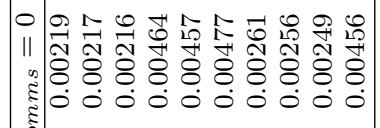
:
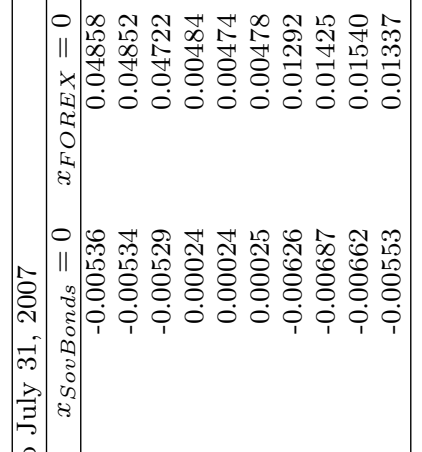

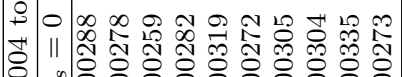

然

索

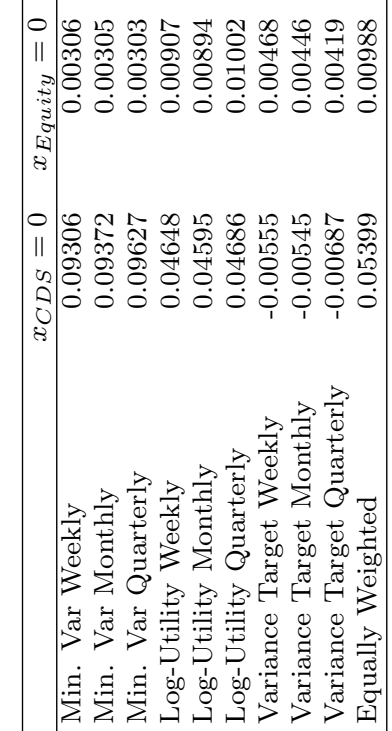

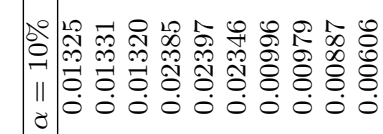

赵 II $\overrightarrow{0}$ b 0000000000

ㅇำㅇำ

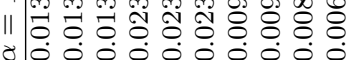

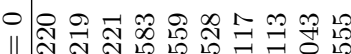

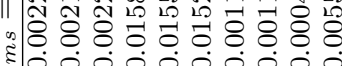

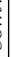

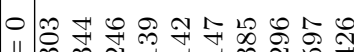

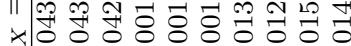

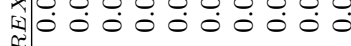

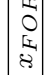

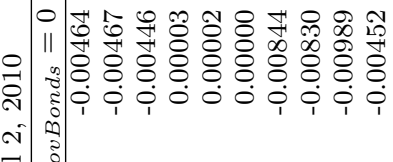

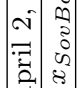

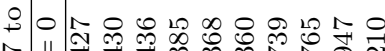

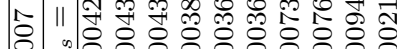

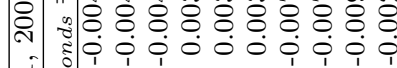

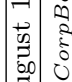

ये

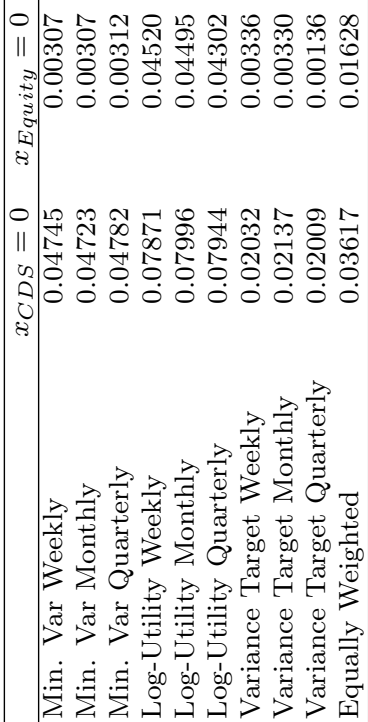




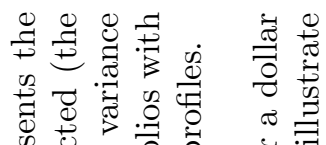

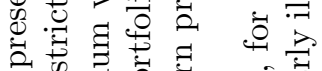
N

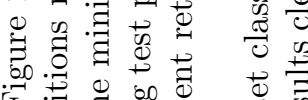

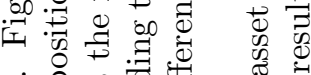

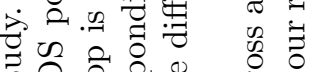

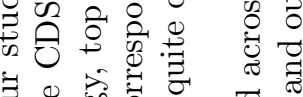

亏ै

.

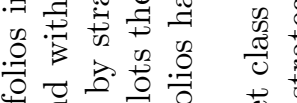

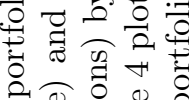

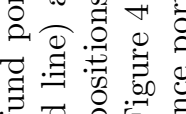

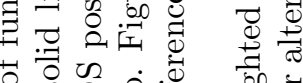

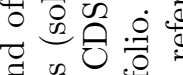

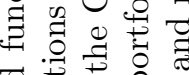

.

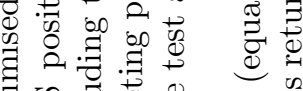

设要

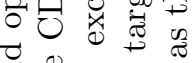

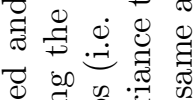

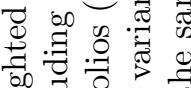

60.000

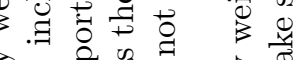

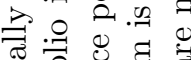

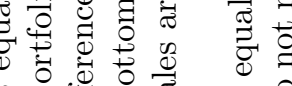

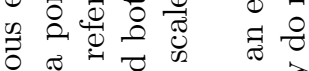

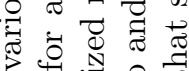

o w $: \because$

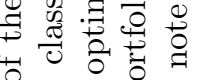

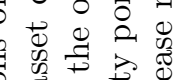

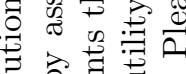

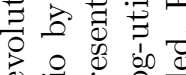

:웡

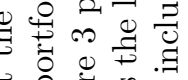

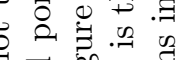

范总

캉

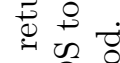

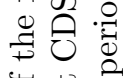

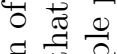

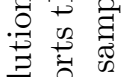

웅

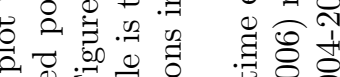

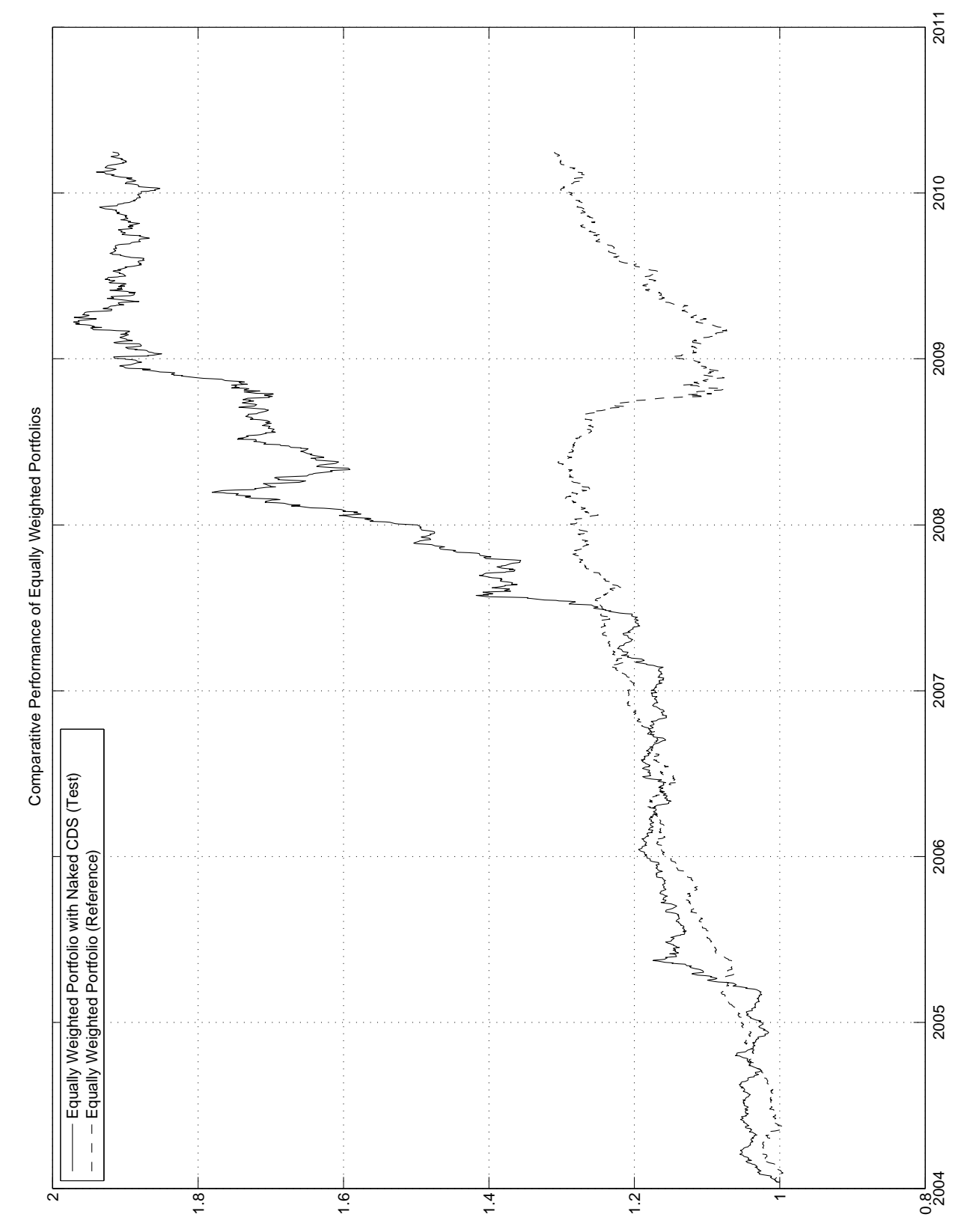

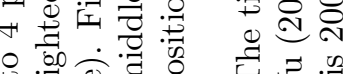

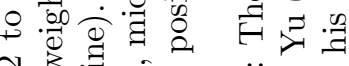

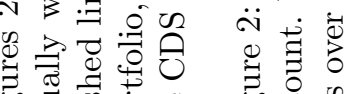

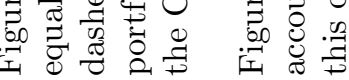



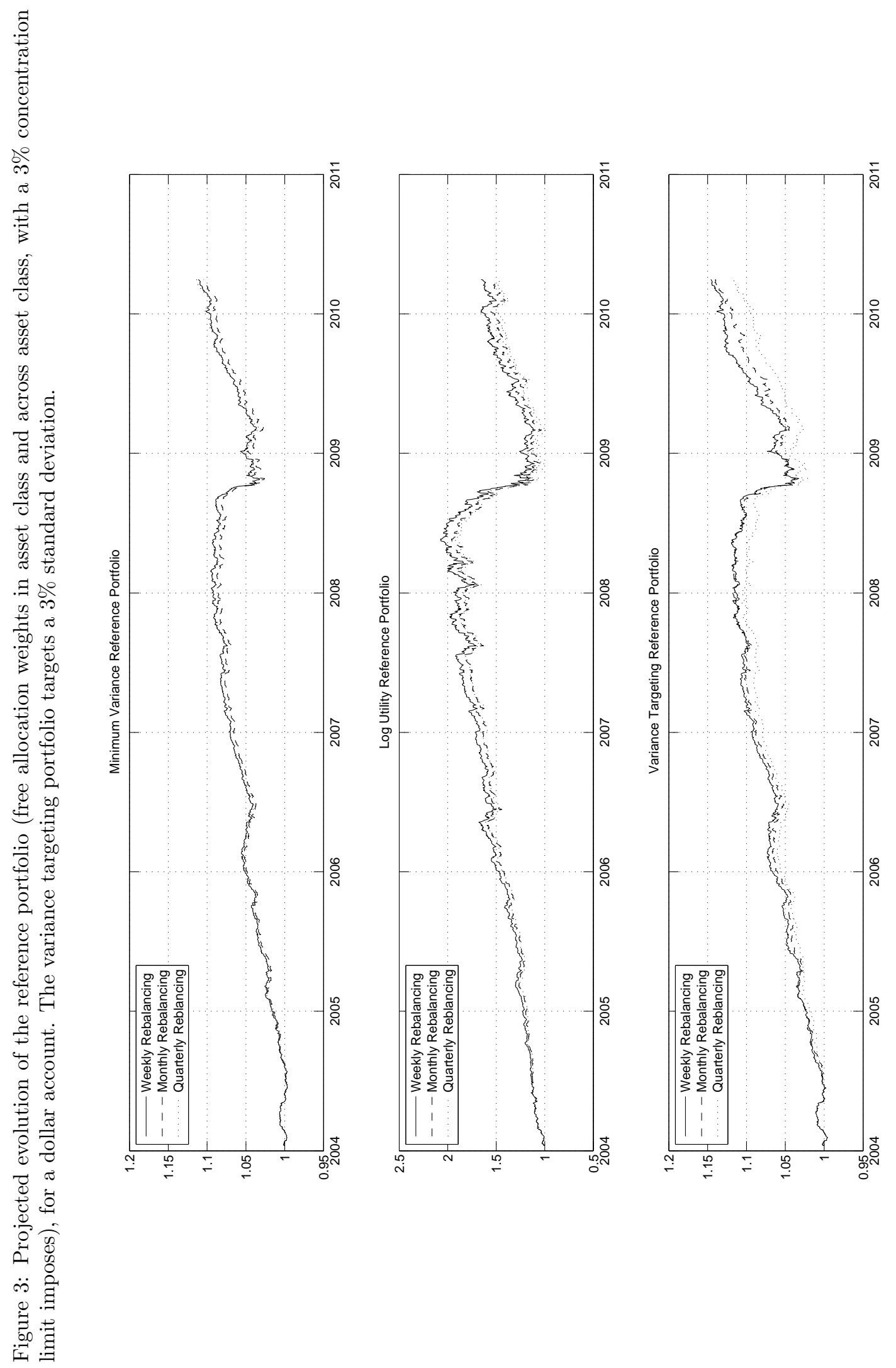

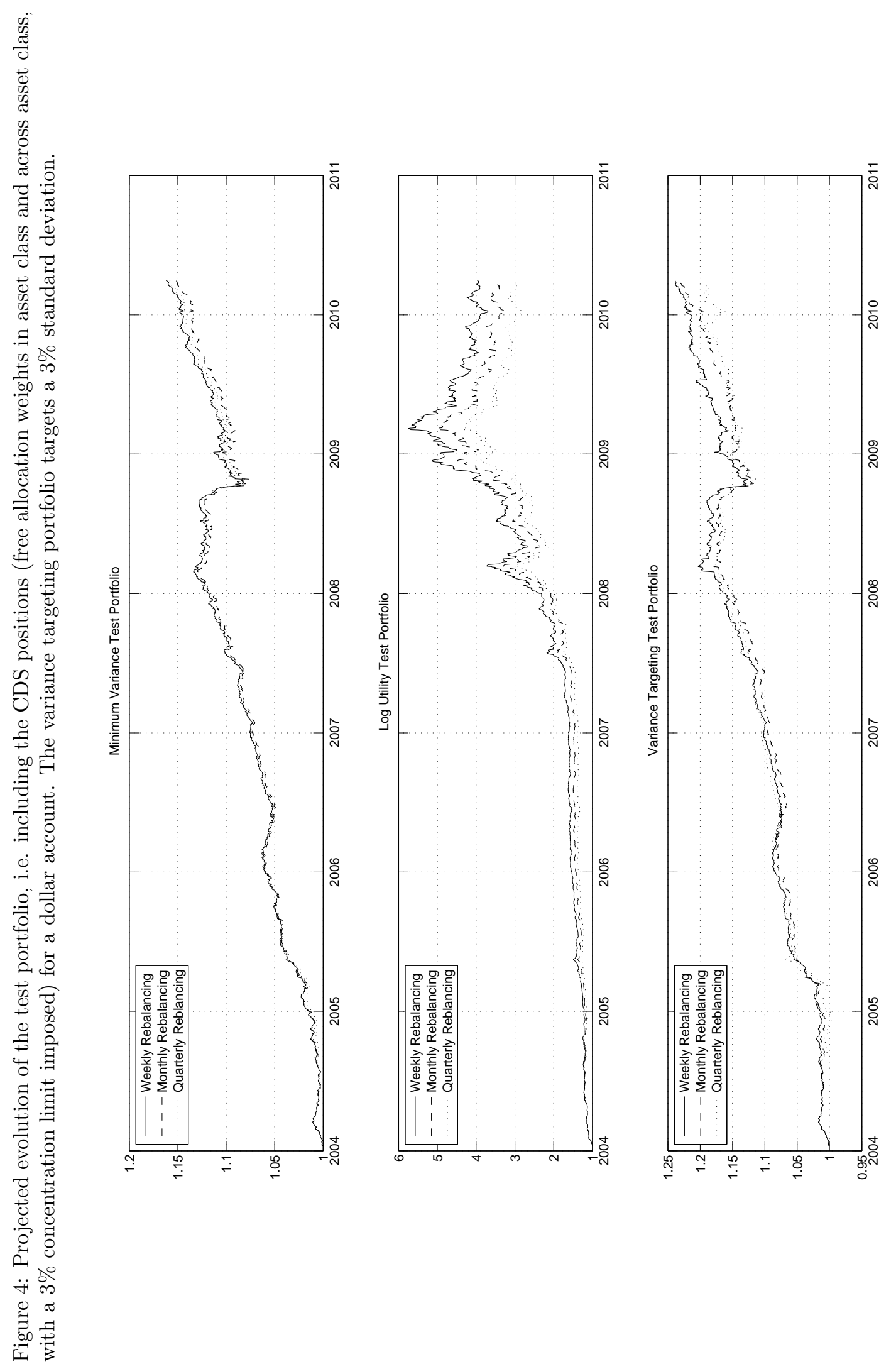


\section{Portfolio Performance and Block Correlations}

Figure 2 in Appendix B plots the comparative evolution of the overall equally weighted (i.e. equally weighted in class and equally weighted across asset classes) test (solid line) and reference (dashed line) portfolios. The portfolios returns reflect the information contained in Table 2. The naive portfolio that includes the naked CDS baskets outperforms the naive portfolio without the CDS position. However, visual inspection of the period January 1, 2004 to July 31, 2007 suggests that the naive portfolio including the CDS positions tracks very closely the naive portfolio netted of the CDS positions. The major bounce in the CDS spreads and subsequent increase in portfolio performance occurs before September 2008, when Lehman Brothers default, an event that has a substantial impact on the value of the naive portfolio with the CDS positions removed.

The naive portfolios offer some interesting insights in the timing of the hedging effect across asset classes of the CDS portfolios. However, the short sample period does not offer a significant long-term scrutiny into the impact of the inclusion of the CDS positions, via for example parametric regression style analysis. Consequently, we must restrict our analysis to the dynamics of the cross section and the impact of mean variance optimising across the asset classes and semi-analysis of the parametric correlation structures.

Figures 3 and 4 in Appendix B present the evolution of the three portfolios strategies optimising the cross section and rebalancing weekly (solid line), monthly (long dashed line) and quarterly (dotted line). It can be seen that the frequency of rebalancing does not substantially change the trajectory of the portfolios. Moreover, there is no evidence of bid-ask spread penalty for more frequent rebalancing. The portfolio descriptive statistics in Table B.10 also describe the portfolio turnovers as a cumulative percentage (100\% represents a complete turnover of the portfolio by value). All portfolios including the CDS positions exhibit lower turnover than their corresponding reference portfolios.

For all rebalancing strategies, the inclusion of the CDS positions in the fund structure reduces the variance and increases returns substantially, although this finding is expected given the inherent nature of the CDS instruments. The magnitude of the change for the logutility investor is substantial: the standard deviations decline, the skewness increases and the 
kurtosis decreases (i.e. first order stochastic dominance) for all rebalancing frequencies. The log-utility investor obtains a 31.03\% average return per annum over the 2004-2010 period with a $14.50 \%$ standard deviation for the test portfolio versus an $11.36 \%$ average annualised portfolio return and a $14.82 \%$ standard deviation for the reference portfolio. However, more critically, the skewness of the reference portfolio is negative whilst the skewness of the test portfolio is positive and the level of excess kurtosis in the test portfolio is almost half that of the reference portfolio for a weekly rebalancing frequency.

Figures B.5, B.6 and B.7 display the time evolution of the block correlations amongst the six asset classes (i.e. across the 255 portfolios and the constituent underlying assets grouped by asset class). Several key aspects emerge from these plots. First, the block correlations are obviously not stable through time and the effect of the financial crisis permeates into the correlation moving average. Second, the dynamics of the minimum correlations, as illustrated in Figure B.6, show that certain positive correlations are highly persistent after mid-2007.

We can see several major changes in the average block correlations over the sample period. Of particular note are the correlation adjustments that occur after the 2007 closure of two hedge funds run by the French bank BNP Paribas. After this event the correlations between the CDS and equity fund returns begins to trend downwards, from approximately $-10 \%$ to $-20 \%$. Furthermore, this trend continues after the Lehman Brothers default event before stabilising at a level below $-20 \%$.

CDS and FOREX positions both exhibit low average correlations with equity. However, the FOREX returns increase rapidly after the onset of the crisis, whilst the CDS correlations sharply decrease, suggesting that in the short-term FOREX positions during times of financial distress may not be as useful as a hedging tool as in non-crisis periods. The average unweighted block correlations do not appear to be informative whereas the maximum correlations provide useful signals for risk management practices. For example, throughout the sample, a number of the equity and FOREX funds exhibit returns close to one in correlation. On the other hand, the estimated correlations for the CDS and commodities asset classes are never above $30 \%$. 
Of the 2,040 daily correlations between the returns on the 51 CDS and 40 equity funds, the highest correlation is approximately $12 \%$ over the entire sample period. The profitability of capital structure arbitrage positions result from this low correlation risk, which is highly persistent throughout the whole crisis period. The average cross correlation is $-0.15 \%$. Hence, this persistent level of diversification is responsible for the lower average correlations in the optimized portfolios. These findings clearly indicate that rebalancing to the lowest block correlations can yield very important gains in terms of risk-return tradeoffs within the macro portfolios of available assets.

Our estimates show that the gain from the inclusion of the CDS funds is not symmetric across strategy types. From Table 4, we can see that, for a log-utility investor rebalancing weekly, the inclusion of CDS funds in the fund of fund mix produces a risk adjusted abnormal return of $31.32 \%$ on a per annum basis relative to the reference portfolio. By contrast, a risk targeting portfolio (targeting a 3\% standard deviation per annum) yields a risk adjusted excess return over the reference portfolio of only $2.29 \%$ per annum for the weekly rebalanced portfolio and $1.94 \%$ for the quarterly rebalanced portfolio.

Interestingly, we find that the mean variance optimisation algorithm with a $3 \%$ objective standard deviation consistently undershoots the targeted level of risk. More specifically, from Table B.10 we can see that the minimisation of risk in the test portfolios is greater than in the reference portfolios. Yet, the standard deviation of the risk targeting test portfolios for weekly and quarterly rebalancing, which are $1.86 \%$ and $2.07 \%$ respectively, still undershoot their target.

A further key finding that emerges from the analysis is the very high level of kurtosis for low risk targeting portfolios. The kurtosis for the weekly reference and test portfolios for the variance targeting strategy is 21.764 and 18.250 respectively, and this is the highest level of kurtosis observed in any of the portfolios. This finding implies that variance targeting underscores standard deviation as a risk measure and subjects the portfolio to higher levels of variation in standard deviation. This is a highly undesirable feature. Both these portfolios are dominated, in terms of first order stochastic dominance, by all of the log-utility strategies whilst, in the second order stochastic dominance, by simple targeting 
the available minimum variance portfolio (note that the minimum variance portfolio has a variable standard deviation as a reference point). This finding is potentially of interest to academics and market participants and is consistent with the anecdotal evidence that hedge funds typically adopt risk targeting strategies for portfolio optimisation.

The minimum variance test portfolio exhibits a $1.48 \%, 1.38 \%$ and $1.35 \%$ risk-adjusted excess returns for the weekly, monthly and quarterly rebalancing. The portfolios exhibit first order stochastic dominance, with lower variance as well as higher returns for the test portfolios over the reference portfolios. Additionally, targeting the minimum variance portfolio does not result in the kurtosis penalties exhibited by the variance targeting portfolios.

Tables B.7 to B.9 in Appendix B also offer interesting insights into the discrepancies between the average correlations from the aggregate equally weighted portfolios presented in Table 3. Noticeably, the skewness of the unweighted block CDS and equity are negatively skewed. However, in the post August 1, 2007 period the skewness is positive, although the average block correlation decreases from -13.42 to $-20.03 \%$.

\section{Discussion}

Our results provide strong empirical evidence that a CDS is not priced as a linear combination of alternatives in the market. Sequential restriction tests and bootstrap resampling indicate that the CDS trading position outlined in $\S(3)$ do not tally with the broad crosssection of alternative assets in the sample. The results from the correlation analysis are of remarkable magnitude. For instance, the average block correlation with corporate debt is virtually zero. Holding corporate debt is generally considered to garner a risk premium. If CDS positions were in effect equivalent to a short position in corporate debt, the correlation and replacement correlations would be expected to be negative and approaching unity. However, this result does not hold. In addition, we see that equity returns are negatively correlated with CDS positions. And remarkably, this correlation is both strong and persistent.

In a recent contribution, Stulz (2009) argues that CDS positions were not responsible for the credit crisis and that their radical shifts in price were symptomatic of a transitory 
mispricing of the intrinsic value of the underlying asset and hence the derivative contract. In similar fashion, we would expect that as the prices of the underlying assets adjusted to account for the changing risk vectors, the prices of the derivative instruments would adjust in a synchronised manner. This pattern, however, is not observable in our dataset, which encompasses most of the single name trades in corporate CDSs.

Furthermore, our empirical evidence appears to contradict this view as it suggests that the returns on CDS positions are uncorrelated with their reference entities and exhibit unstable positive and negative time varying correlations with a variety of other assets across the market. Interestingly, we show that relative to a linear reference benchmark, the CDS positions offer roughly a $28 \%$ return in excess for a log utility maximising investor rebalancing weekly. Investors in effect do not receive an adequate risk premium for holding debt, but they are compensated with a substantial premium for holding the equivalent protection (i.e. being short in the debt). The fact that the portfolio returns, comprising CDS, are not replicable by any other linear combination is indicative of this decoupling.

From these results we conclude that a traded CDS position can be regarded as a unique Arrow-Debreu asset over the 2004-2010 period. Furthermore, the notion that the returns on CDS positions have decoupled post mid-2007 lends supports to the arguments put forward by Geanakoplos (2009) suggesting that the introduction of CDSs midway through the leverage cycle allowed speculators to drive default risk higher via the excessive trading of CDS positions. This trading boom resulted in the explosive increase in the notional amounts of defaultable bonds protected by these instruments, via the trading mechanism suggested in $\S(3)$. Furthermore, once the feedback mechanism created by the separation of ownership between creditors and insurers had been enshrined, default risk became a marketable and desirable outcome for speculators in this asset class.

In summary, we find strong evidence to suggest that the introduction of CDS contracts in late 2004 does appear to have resulted in a contagious decoupling of the CDS spreads from their reference assets. Over the financial crisis period, the evolution of CDS spreads defined a class of assets with unique asset price dynamics, relative to other alternatives. In this case the financial benefit is asymmetric as the holders of naked protection enjoy a substantial 
premium that affects multiple asset classes across the spectrum of available assets.

\section{Conclusions}

The contribution of this paper is to show that the introduction of naked CDS positions in a broad highly diversified fund of funds portfolios results in a substantial adjustment in the portfolio's return and risk profile. Specifically, the results show that investing in a naked CDS position yields and excess return of roughly $28 \%$ per annum and a corresponding important reduction in correlation.

We find that the degree of risk diversification is highly significant. In addition, we show that the effect in terms of risk return of an exclusion of the CDS returns in relation to a broad set of portfolios in alternative assets cannot be replicated and is significantly different from a random restriction.

To overcome the limitation of a relatively short sample period, we utilise a very broad cross section of assets and compute average cross correlations. We find significant and robust evidence of negative correlations between the returns on baskets of CDS positions and a variety of equity, commodity and foreign exchange baskets. We document that portfolios that include all of the available CDS positions, over the period January 1, 2004 to April 2, 2010, exhibit first order stochastic dominance over portfolios with a restricted set of instruments.

The risk-return properties of this class of assets appears to be substantially at odds with the rest of the market. In particular, the low block correlation (average of a large number of cross correlations between asset classes) between the CDSs and bond sub-portfolios indicates that the price evolution of the CDS spreads appear to have decoupled from the fundamental structure of their underlying contracts.

Collectively, the empirical results presented here raise a key question of market policy: are naked CDS contracts beneficial? Our results provide empirical support for the view that CDS positions can offer additional benefits beyond their natural purpose. Therefore, these findings have at least two noteworthy implications. First, these systematic abnormal returns are inherently unstable and could potentially initiate a bubble in CDS prices. Second, the 
evolution of risk premia appear to hedge out exposure to the leverage cycle and the return profile realistically reflects default risk.

Taken together, our findings highlight the potential benefits of CDS contracts for speculative investors, whereas the social benefits are evidently questionable. It is evident that the leveraging of short positions produces effects beyond the originally conceptualised design of a CDS contract. Whether centralised clearing houses and a more transparent mark to market price would result in greater social benefits is still unclear. Going forward, nevertheless, it appears likely that clearing house margins and collateral arrangements will reduce the incentive problem inherent in such a highly leveraged transaction.

In summary we have provided a large scale testing framework for analysing the replicability of new asset classes within a standard portfolio analysis framework. The procedure currently makes use of the first and second moments and comoments to assess replicability of asset returns under a variety of portfolio optimisation regimes. The procedure will be familiar to practitioners using out of sample backtesting models, rather than regression based structural decompositions. Variations on this approach are gaining traction in the academic literature, see for instance Campbell et al. (2010) and Kyj et al. (2010), which allow for the identification of dominant portfolios. Future work will consider higher frequency realized covariance and higher moments within the portfolios and a wider variety of CDs. 


\section{References}

1. Acharya V. V., Johnson C. T., 2007. Insider trading in credit derivatives. Journal of Financial Economics, Vol. 84, No. 1, pp. 110-141.

2. Bielecki, T. R., Jeanblanc, M., Rutkowski M., 2005. Pricing and trading credit default swaps under deterministic intensity. Unpublished working paper, Isaac Newton Institute for Mathematical Sciences, Cambridge.

3. Bielecki, T. R., Rutkowski M., 2002. Credit Risk: Modeling Valuation and Hedging. Springer-Verlag, Berlin Heidelberg New York.

4. Bolton, P., Oehmke, M., 2010. Credit Default Swaps and the Empty Creditor Problem. Columbia University Working Paper Series.

5. Brigo, D., Mercurio, F., 2005. Interest Rate Models - Theory and Practice, Second Edition, Springer Finance

6. Campbell, J. Y., Serfaty-De-Madeiros, K., Viciera, L. M., 2010. Global currency hedging. Journal of Finance, Vol. 65, No. 1, pp. 87-123.

7. Fostel, A., Geanakoplos, J., 2008. Leverage cycles and the anxious economy. American Economic Review, Vol. 98, No.4, pp. 1211-1244.

8. Geanakoplos, J., 1997. Promises, Promises. In W.B. Arthur, S. Durlauf and D. Lane (eds.), The Economy as an Evolving Complex System, II. Reading MA: Addison-Wesley, 1997, pp. 285-320.

9. Geanakoplos J., 2009. The leverage cycle, in D. Acemoglu, K. Rogoff and M. Woodford, eds., NBER Macroeconomics Annual 2009, Chicago: University of Chicago Press, Vol. 24, pp. 1-65.

10. Hatemi, J. A., Roca E., 2006. A re-examination of international portfolio diversification based on evidence from leveraged bootstrap methods. Economic Modelling, No. 22, pp 993-1007.

11. Hu, H. T. C., Black, B., 2008. Debt, Equity, and Hybrid Decoupling: Governance and Systematic Risk Implications. European Financial Management, Vol. 14, No. 4. pp. 663-709.

12. Instefjord N., 2005. Risk and hedging: do credit derivatives increase bank risk? Journal of Banking and Finance, No. 29, pp. 333-345.

13. Karatzas, I., 1996. Lectures on the Mathematics of Finance. CRM Monograph Series 8, 148 pp. American Mathematical Society. The Andre Aisenstadt Lectures at the University of Montreal, May 1996.

14. Karatzas, I., 2006. A Survey of Stochastic Portfolio Theory. The Eugene Lukacs Lectures, Bowling Green University, May-June 2006.

15. Kroner, K., Sultan, J. (1993). Time Varying Distributions and Dynamic Hedging with Foreign Currency Futures. Journal of Financial and Quantitative Analysis, Vol. 28, No. 4. 535-551. 
16. Kyj, L. M., Ostdiek, B., Ensor, K., 2010. Covariance estimation in dynamic portfolio optimization: a realized single factor model. American Finance Association 2010 Atlanta Meetings Paper.

17. Longstaff, F.A., Pan, J., Pedersen, L. H. and Singleton, K. J., 2010. How sovereign is sovereign credit risk? American Economic Journal: Macroeconomics, forthcoming.

18. Longstaff F. A., Rajan A., 2008. An empirical analysis of the pricing of collateralized debt obligations. Journal of Finance, Vol. 63, No. 2, pp. 529-563.

19. Jondeau E., Rockinger M., 2006. Optimal Portfolio Allocation under Higher Moments. European Financial Management, Vol. 12, No. 1, pp. 29-55.

20. Martellini L., Ziemann V., 2010, Improved Estimates of Higher-Order Comoments and Implications for Portfolio Selection. Review of Financial Studies, Vol. 23, pp. 1467-1502.

21. Merton R. C., 1973. Theory of Rational Option Pricing. The Bell Journal of Economics and Management Science, Vol. 4, No. 1, pp. 141-183.

22. Muirhead, R. J., 1981, Aspects of Multivariate Statistical Theory. John Wiley \& Sons, New Jersey.

23. Musiela, M., Rutkowski, M., 2005. Martingale Methods in Financial Modelling. Springer-Verlag, Berlin Heidelberg.

24. Pesaran, M. H., Schleicher, C., Zaffaroni, P., 2009. Model averaging in risk management with an application to futures markets. Journal of Empirical Finance, Vol. 16, pp. 280-305.

25. Shadab, H. B., 2009. Guilty by association: regulating credit default swaps. Entrepreneurial Business Law Journal, Vol. 4, No. 2.

26. Stulz, R. M., 2010. Credit default swaps and the credit crisis. Journal of Economic Perspectives, Vol. 24, No. 1, pp 73-92.

27. Wagner W., 2007. The liquidity of bank assets and banking stability. Journal of Banking and Finance, Vol. 31, pp. 121-139.

28. Yu F., 2006. How profitable is capita; structure arbitrage. Financial Analysts Journal, Vol. 62, pp. 47-62. 


\section{Appendix A. Asset Class Returns Methodology}

Our guiding principle for each asset class is that all coupons, dividends and other returns over the capital value are reinvested in an identical asset or position. For instance in the case of a CDS a long position would receive inflows from quarterly payments and are then assumed to be reinvested in additional short protection, for a market neutral position.

\section{Appendix A.1. Foreign Exchange Funds}

For the FOREX and commodities funds, we use existing broad based baskets that are currently available to benchmark several ETFs. These are provided by J.P. Morgan and Standard \& Poor's/Goldman Sachs, respectively. The remaining four asset classes are subdivided into fund baskets aggregated from individual tradeable positions. In essence, for each basket we conceive of an available ETF that tracks the positions, transaction cost adjusted. CDS returns are equally weighted and quoted as spread bid to spread ask and the motivation for this return calculation is described in $\S(3)$. Defaults are recorded, but we assume that they are fully offset. Therefore, we are only interested in the return on the realized calendar spread (see $\S(3))$.

\section{Appendix A.2. Equity Funds}

For the equity positions, we consider funds that are exposed to the complete cross section of US, UK, EMU and Japanese stocks. The indices are total return in the sense that dividends are assumed to be reinvested in the fund. Moreover, transaction costs are adjusted on a daily basis via the daily average bid-ask spread.

\section{Appendix A.3. Corporate Bond Funds}

Returns on corporate bonds are computed using the Merrill Lynch-Bank of America bond index total return methodology. This methodology assumes that gross coupons are reinvested into the bonds. For a basket of $k$ bonds, the total return is $R I_{t}=R I_{t} \tilde{A}_{t} \tilde{B}_{t}^{-1}$ where $\tilde{A}_{t}=\sum_{i=1}^{k}\left(P_{i, t}+A_{i, t}+C P_{i, t}\right) N_{i, t-1}$, $\tilde{B}_{t}=\sum_{i=1}^{k}\left(P_{i, t-1}+A_{i, t-1}+C P_{i, t-1}\right) N_{i, t-1}, P$ is the clean price of the $i^{t h}$ bond at time $t$, adjusted for any partial serial redemptions. $A$ is the accrued interest to the 'normal' settlement date. $N$ is the nominal value of amount outstanding, if known, otherwise the issued amount and $C P$ is an adjustment made for bonds that have ex-dividends. The discrepancy between the number of fund baskets for the CDS, equity and corporate bond baskets is due to the industry classification used to identify each instrument. For the CDS positions, the industry identifier is derived from the underlying corporate bond. In total, there are 60 unique available country-sectors identified on the CMA database, from which we draw 51 CDS positions. For equities, one digit SIC codes are used and this generates 40 unique fund baskets. Unfortunately, the level 
of overlap for each country-sector is not perfectly uniform for the SIC codes. The total return on sovereign bond baskets are computed in the same way as the return on corporate baskets and we include all of the bonds in the Merrill Lynch-Bank of America bond tracker funds. Source: Thomson Reuters and Bank of America.

\section{Appendix A.4. CDS Funds}

Our short CDS funds are assumed to track the spreads. Similarly to the other funds in our exercise we assume that any default events are reinvested. This is somewhat problematic to simulate as the fund maybe leveraged at any value. So we use the following rule

Consider an individual spread $\kappa^{i}(t)$, the return on a notional position $V^{i}(t)$ invested in $N$ CDS contracts. Assuming that no default event occurs the day on day return for rolling the position is

$$
r^{i}(t, t+\Delta t)=\log V^{i}(t+\Delta t) \kappa^{i}(t+\Delta t)-\log V^{i}(t+\Delta t) \kappa^{i}(t+\Delta t)
$$

and in the event of a default, the return is

$$
r^{i}(t, t+\Delta t)=\log V^{i}(t+\Delta t)-\log V^{i}(t+\Delta t) \kappa^{i}(t+\Delta t) .
$$

An attractive feature of modeling a fund with this type of continuously rebalanced CDS position is that the capital outflow in the swap is paid in discrete instalments. Hence, the cost of carrying of the CDS can be ignored as it is a daily back to back transaction.

Stripping out the recorded credit events (the largest non recovery was 40\%) and only including mark to returns without the default information, results in an identical portfolio turnover and return profile to three decimals.

\section{Appendix A.5. Equally weighted portfolio construction}

The equally weighted portfolio is constructed as follows

Asset Class Weights The weights are divided $\frac{1}{6}$ by asset class.

Fund basket weights The weights are then divided equally by the number of funds in each class. Therefore for each of the $51 \mathrm{CDS}$ sector fund baskets the weighting is $\frac{1}{306}$.

\section{Appendix B. Internet Appendix}

The annexes to this paper are arranged as follows. Table 2 reports the descriptive statistics for aggregate equally weighted portfolios by asset class over the whole sample period. Table 3 reports the average aggregate 
sample linear correlations for this equally weighted asset class portfolios. Figure 2 shows the evolution of a fund of fund equally weighted by asset class (i.e. the portfolio formed by equally weighting the six asset class portfolios. The dotted line represents the equally weighted portfolio of the five asset class portfolios without the CDS asset class portfolio). Figure 3 presents the evolution of the 9 reference portfolios (without CDS positions) divided into three subplots of strategy type. Each plot reports the returns on the weekly, monthly and quarterly rebalanced portfolios. Figure 4 presents the evolutions of the test portfolios (with CDS included) for the three strategies and plots the relative evolutions of the alternative rebalancing frequencies. Figure B.5 reports the evolution of the average unweighted block correlations across asset classes (i.e. at the individual fund type level, see Figure B.6). Figure B.6 depicts the evolution of the minimum observed unweighted block correlations and the evolution of the maximum observed unweighted block correlations are reported in Table B.7.

Table B.6 lists the 255 funds/baskets used to construct the block correlations. The CDS baskets consist of equally weighted naked positions with returns driven by adjustments in the cost of protection outlined in $\S(3)$ and categorised by sector. The equity funds consist of all equities listed in the US, UK, EMU and Japan weighted by capitalization and categorised by sector. The corporate debt baskets consist of all corporate bonds and all available maturities for the US, UK, EMU and Japan categorised by sector. The sovereign debt baskets consist of bonds indices categorised by maturity and country for the US, UK, EMU and Japan. The FOREX baskets are dollar indices based on available spot and future rates from the Merrill Lynch-Bank of America Trade Weight Indices. The commodities baskets are broad multi horizon baskets consisting of spot and futures returns for commodities and are provided by Standard \& Poor's.

Tables B.7, B.8 and B.9 shows the descriptive statistics of the distribution of block correlations by asset class (including correlations within asset class) over the whole sample, between January 1, 2004 and July 31, 2007 and from August 1, 2007 to April 2, 2010 respectively. Table B.10 reports the descriptive statistics for the various portfolio strategies (test and reference) over the whole sample period. 

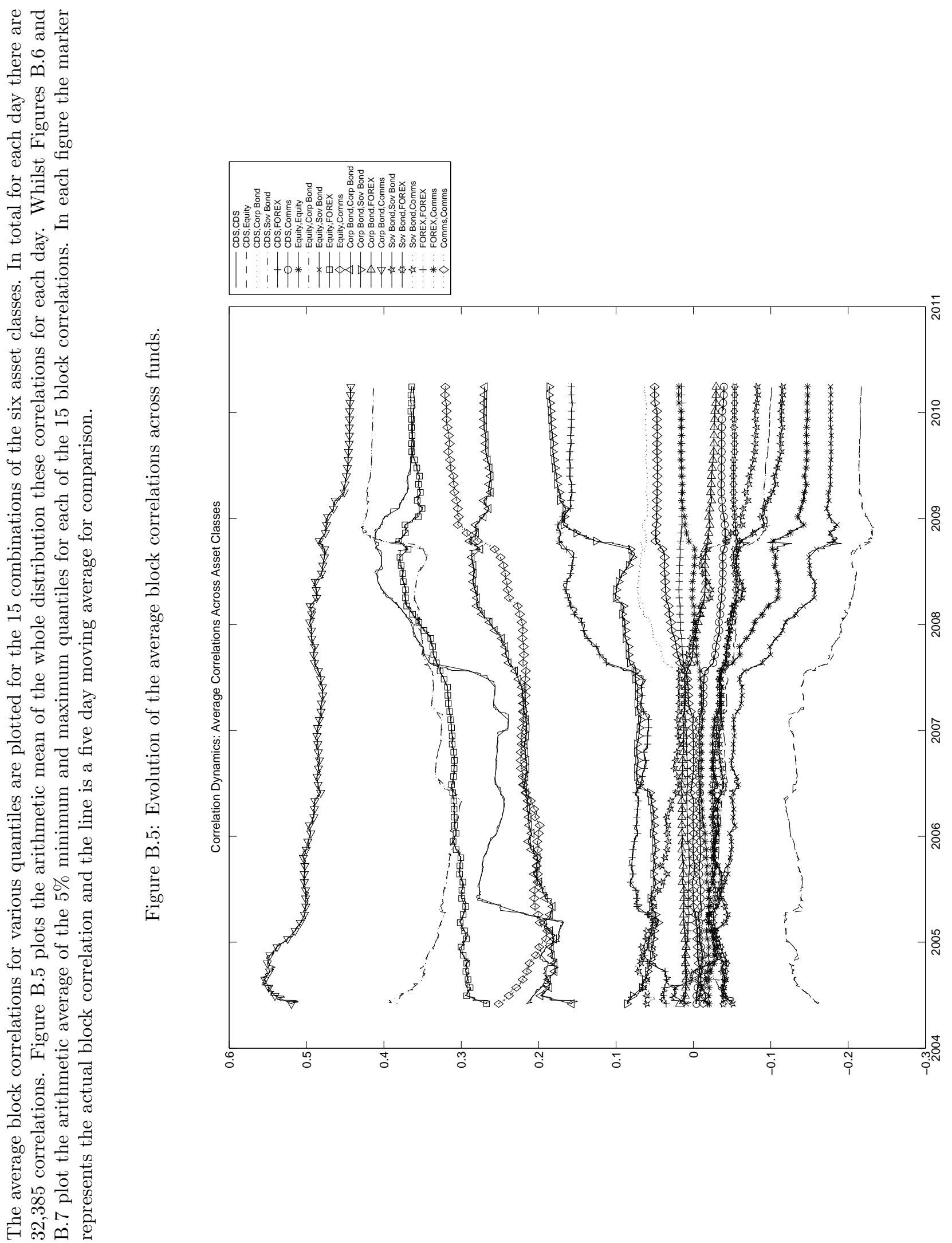


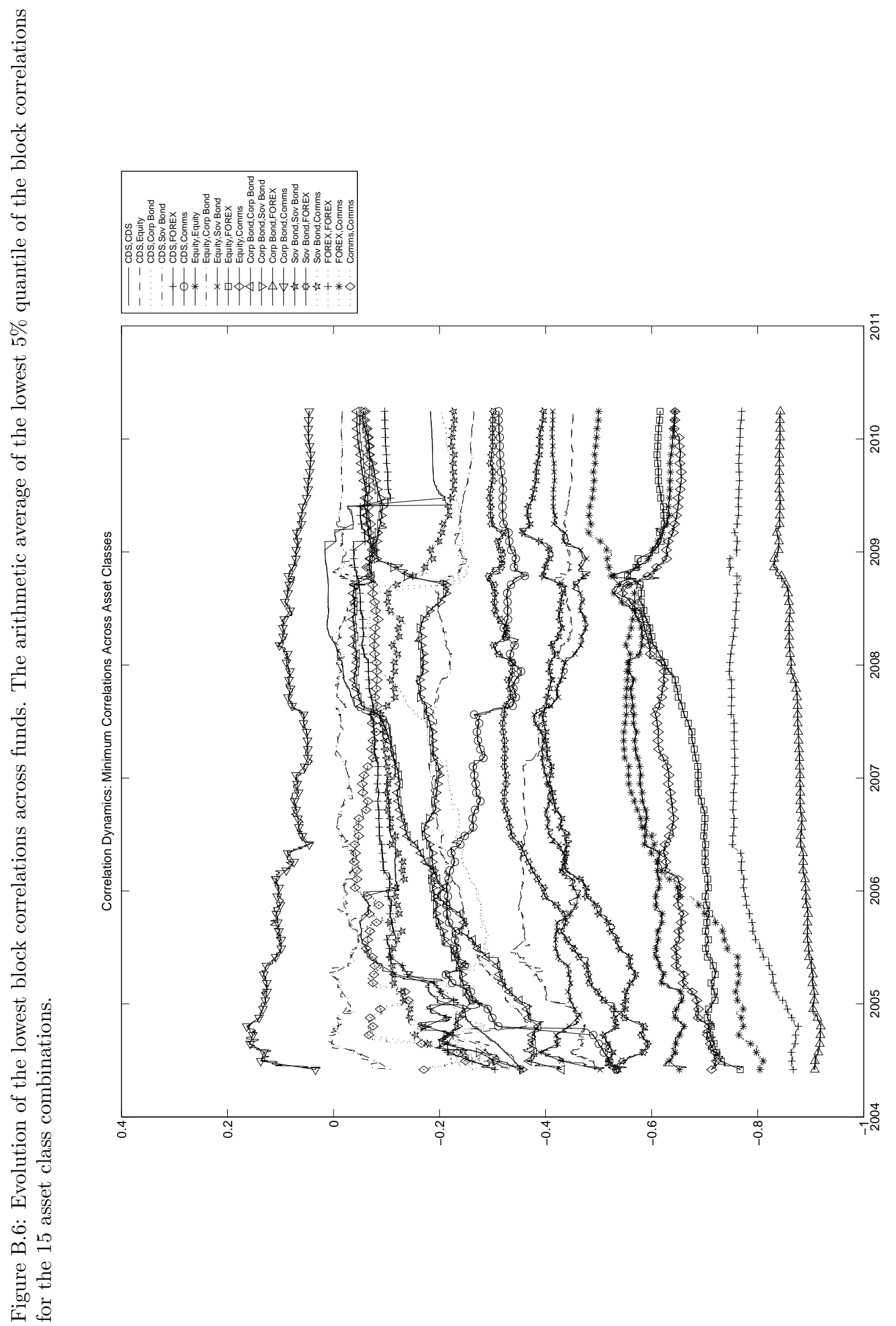



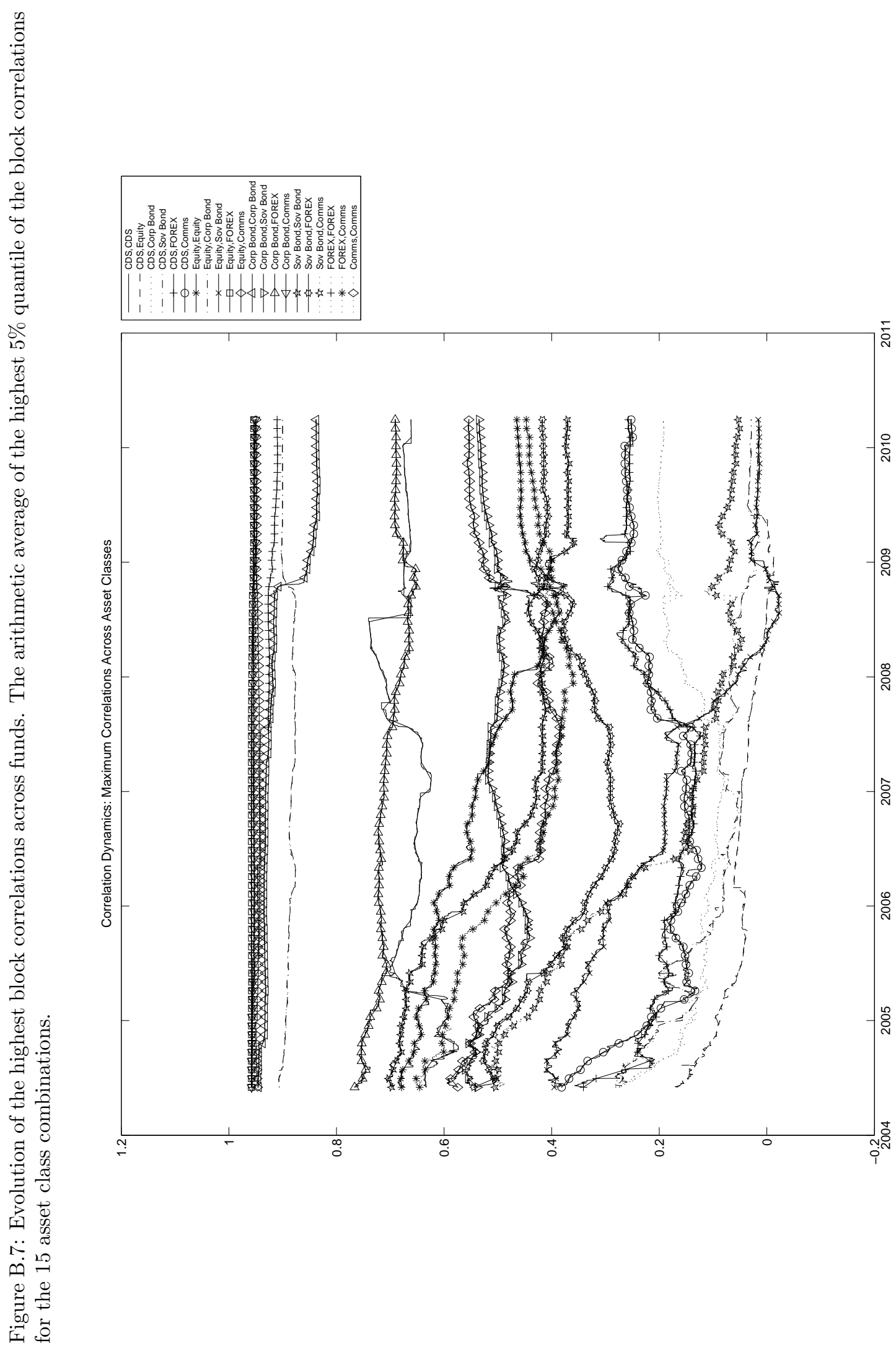


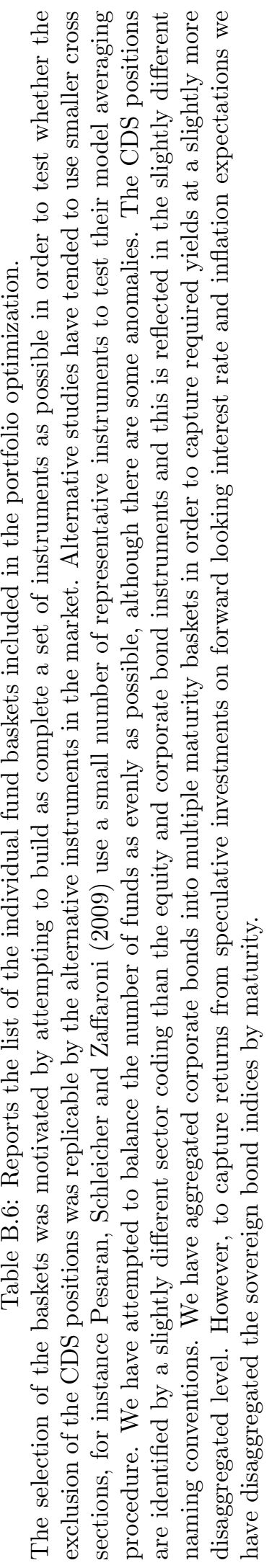

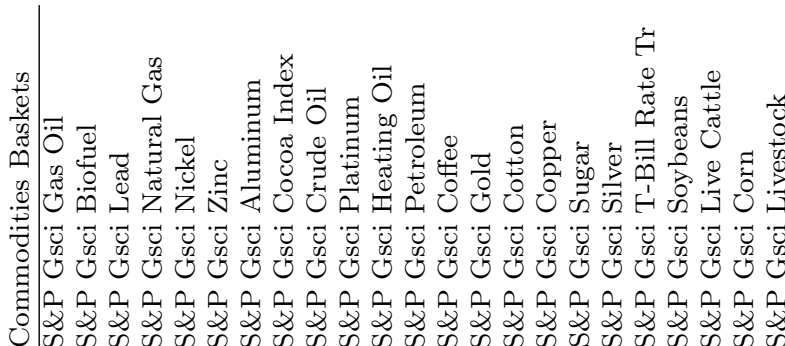

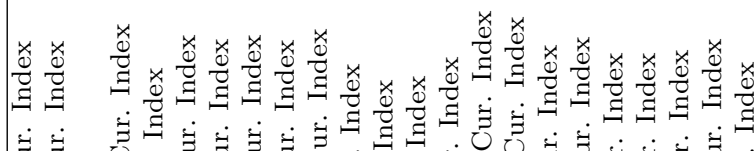

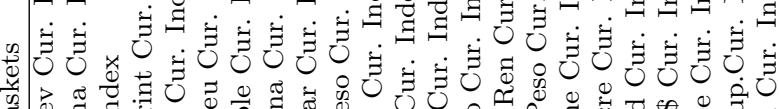

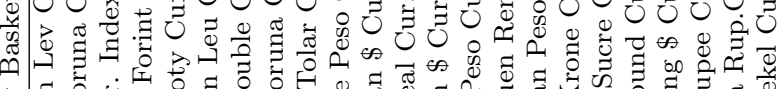
.

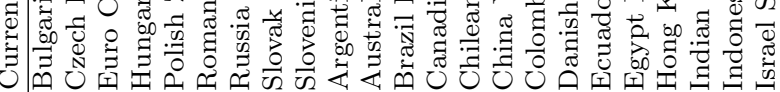

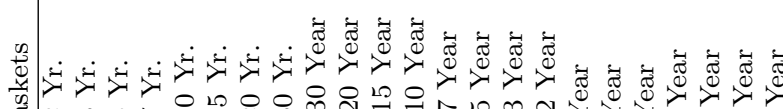

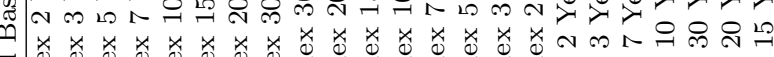

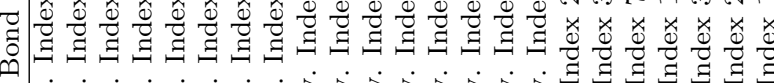

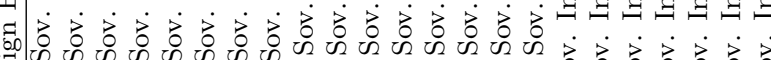

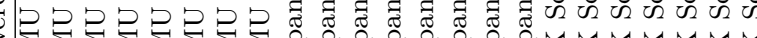

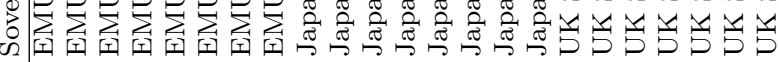

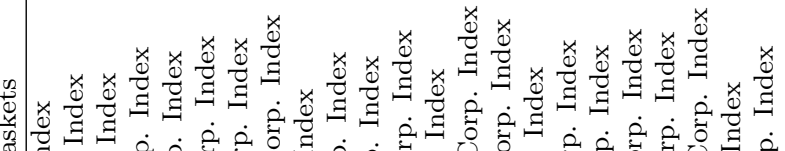

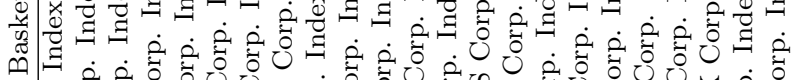

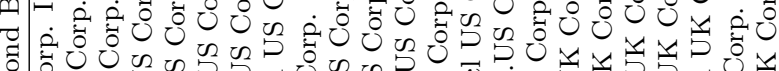

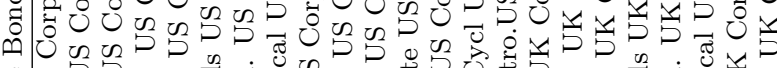
$\begin{array}{llll} & \\ 0\end{array}$

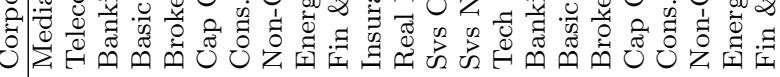

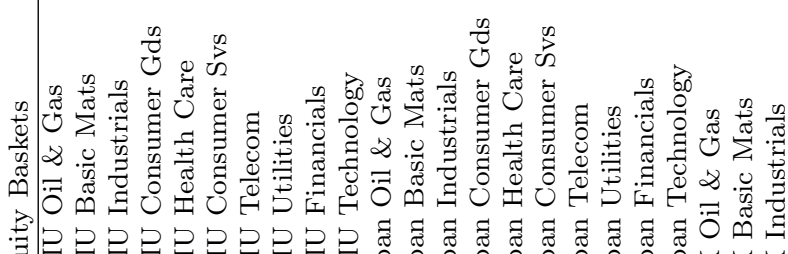

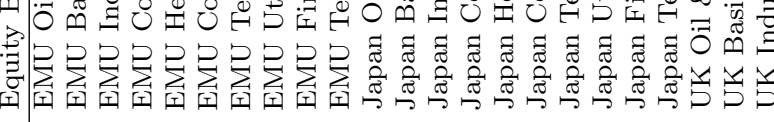

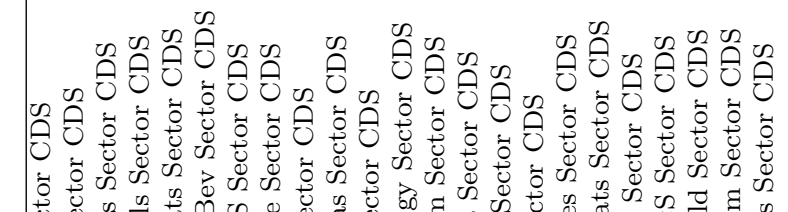

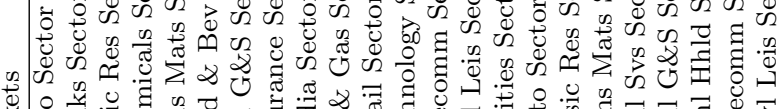

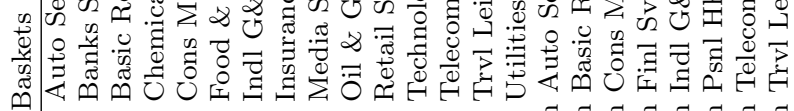

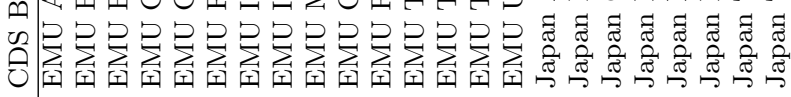




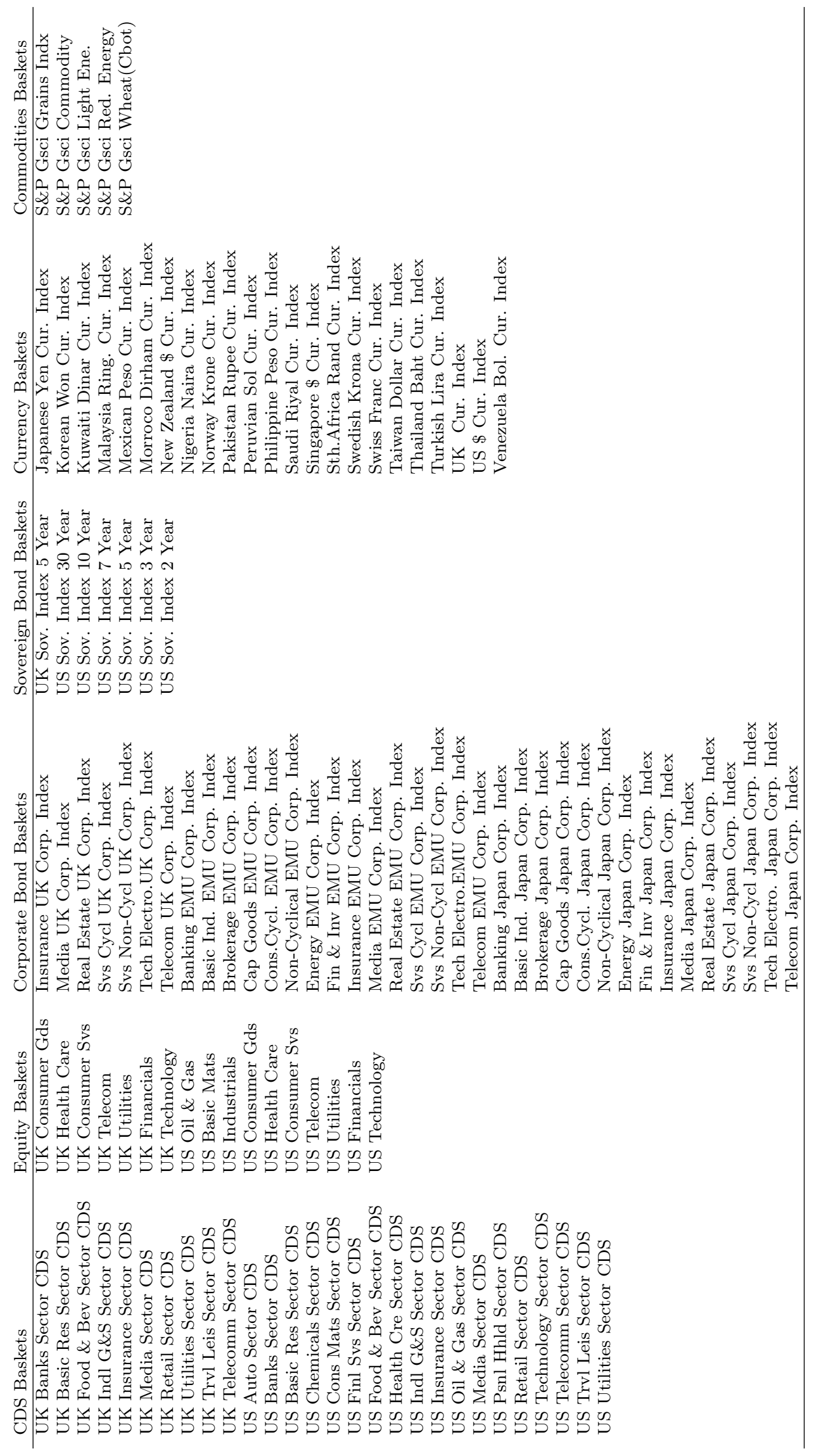




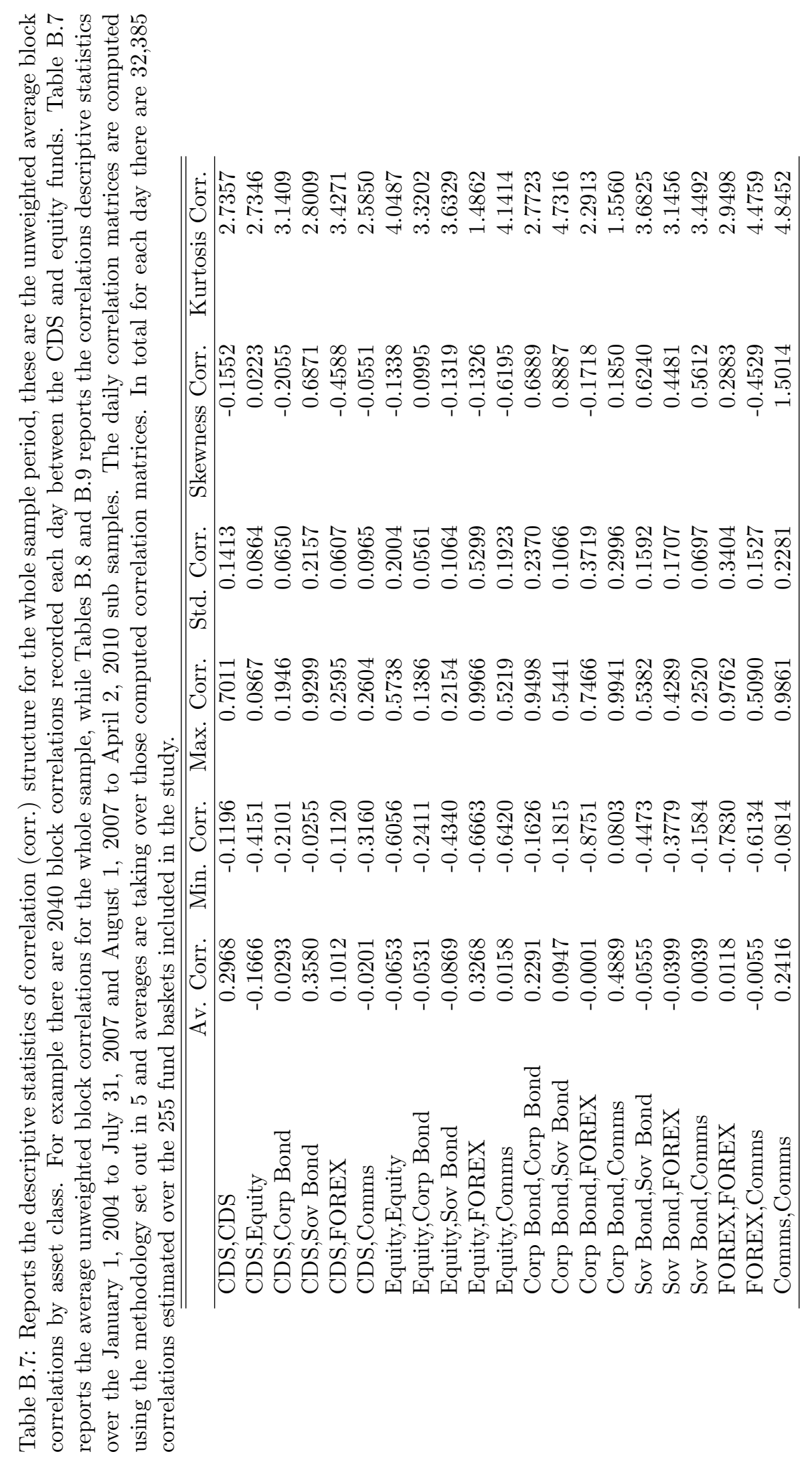




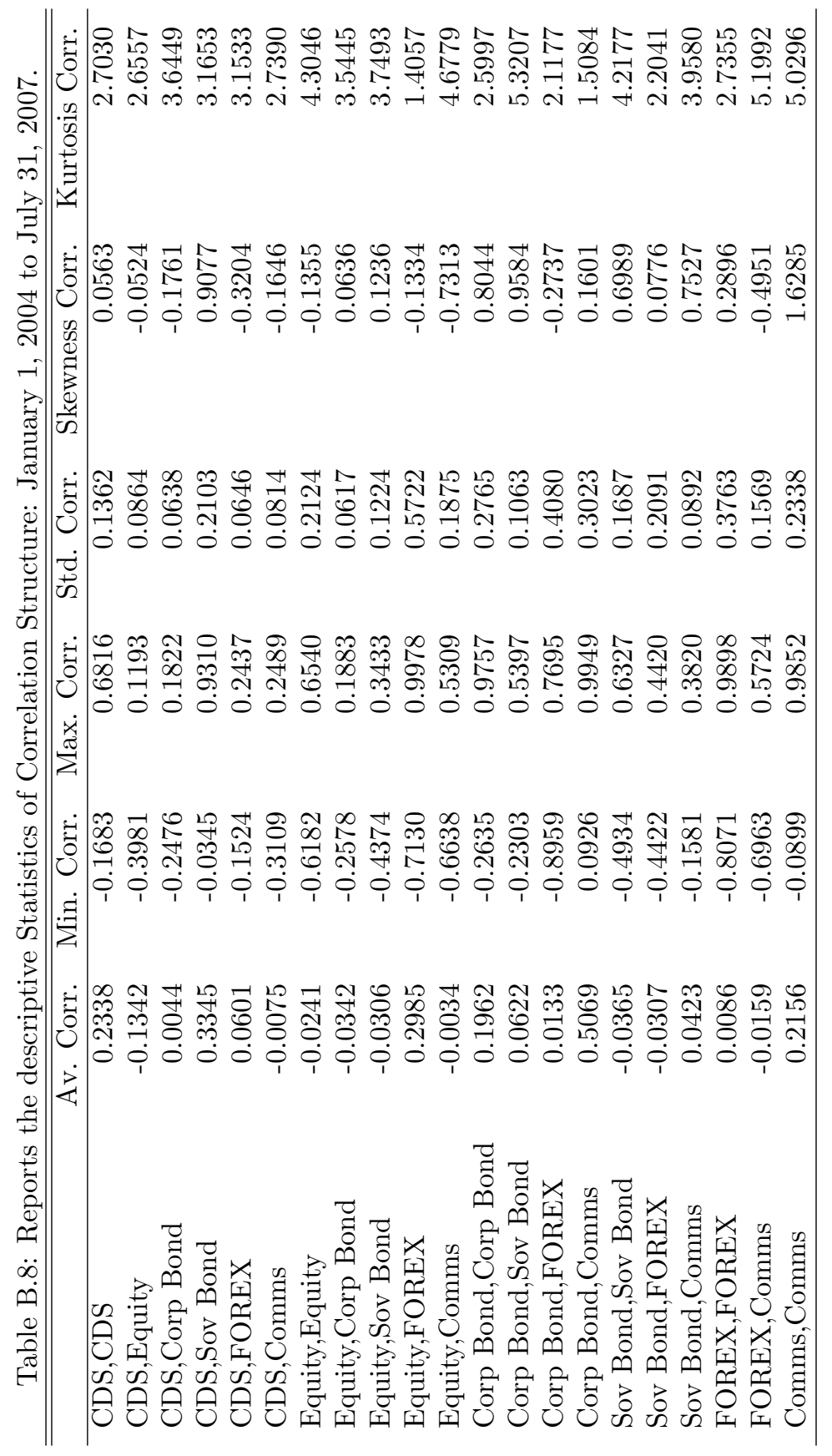




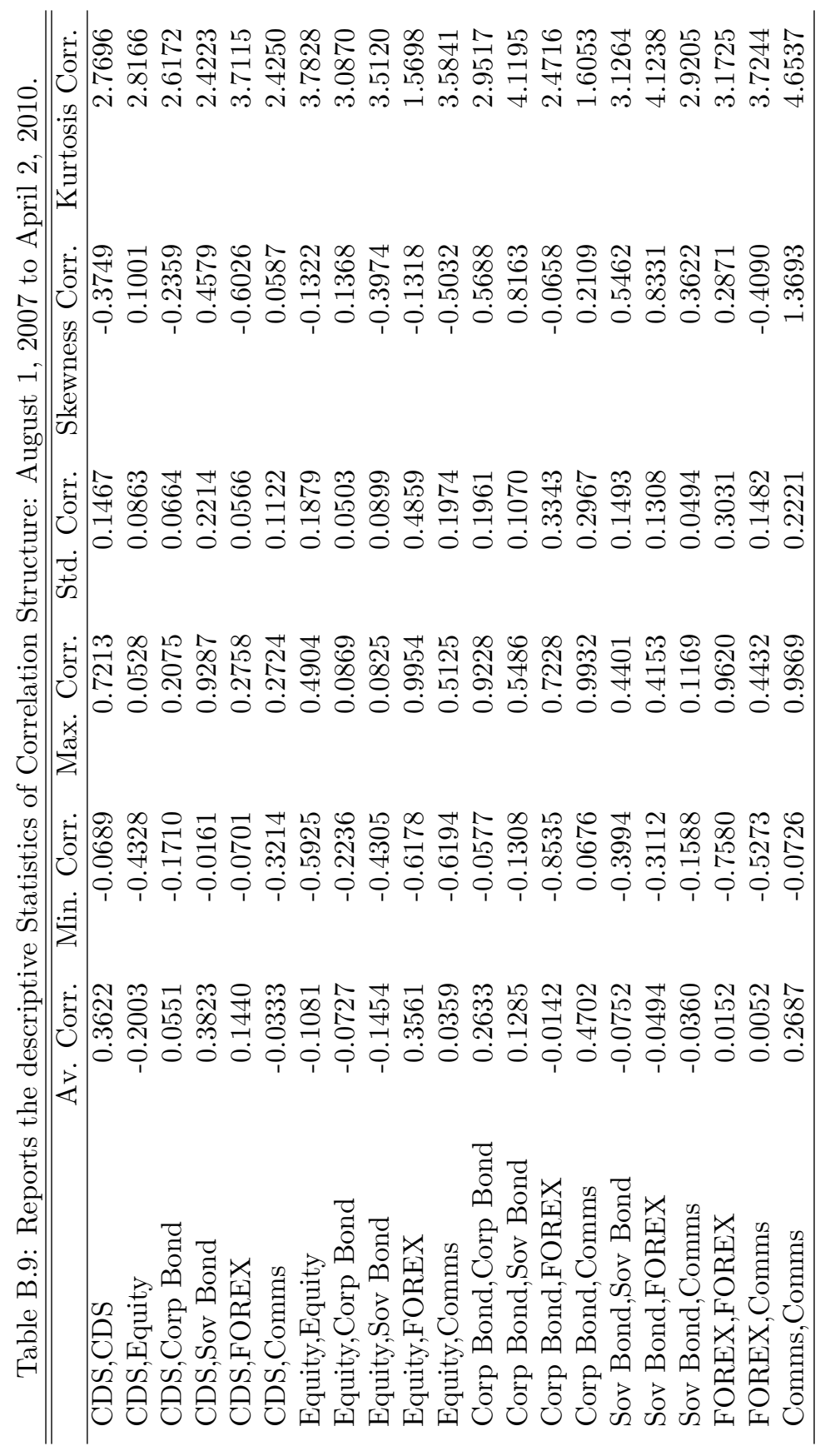




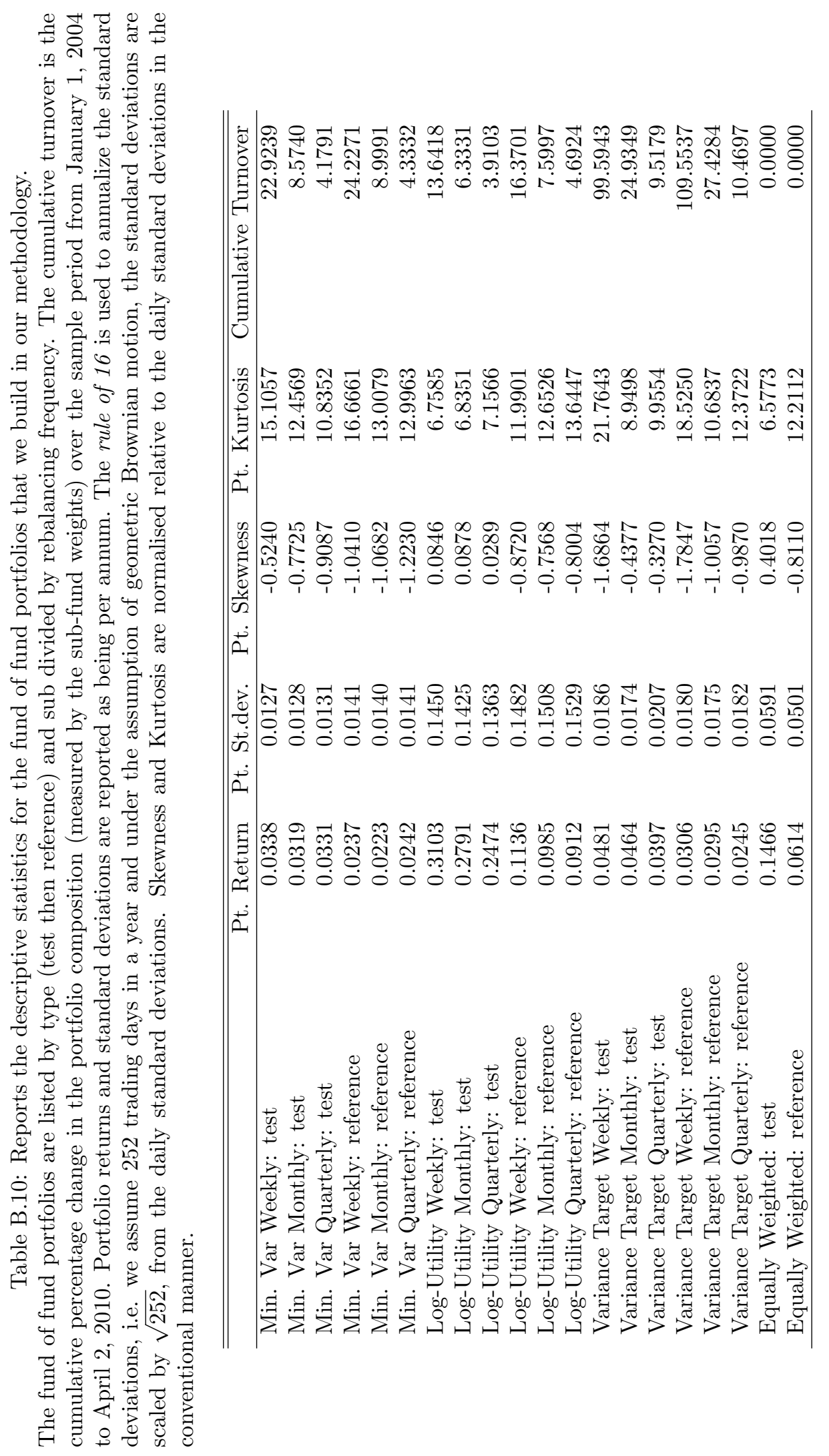

